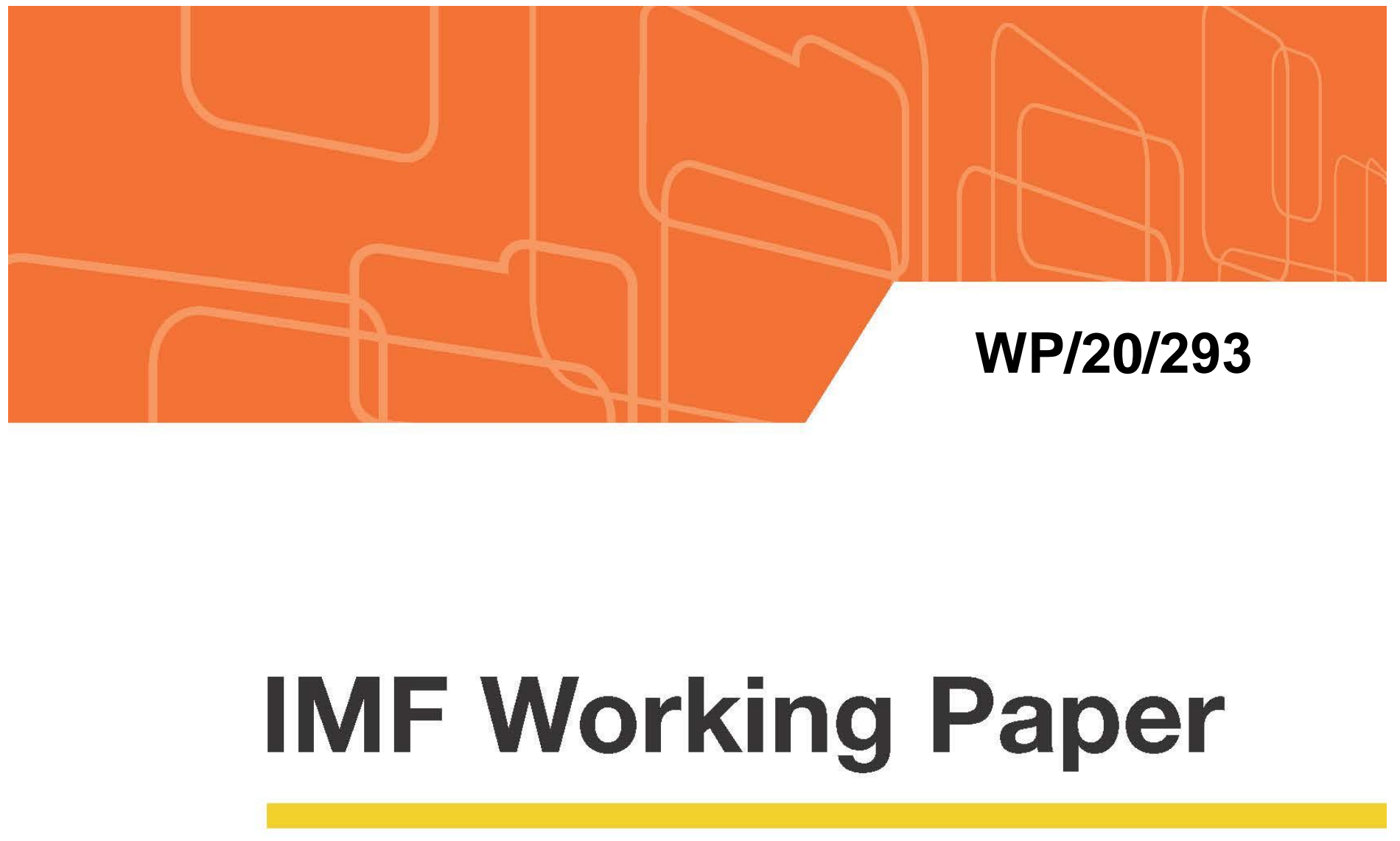

\title{
The Aggregate-Demand Doom Loop: Precautionary Motives and the Welfare Costs of Sovereign Risk
}

\author{
by Francisco Roldán
}

IMF Working Papers describe research in progress by the author(s) and are published to elicit comments and to encourage debate. The views expressed in IMF Working Papers are those of the author(s) and do not necessarily represent the views of the IMF, its Executive Board, or IMF management.

$$
\text { I N T E R N A T | O N A L M O N E T A R Y F U N D }
$$


(C) 2020 International Monetary Fund

$\mathrm{WP} / 20 / 293$

\title{
IMF Working Paper
}

Research Department

The Aggregate-Demand Doom Loop:

Precautionary Motives and the Welfare Costs of Sovereign Risk

Prepared by Francisco Roldán

Authorized for distribution by Deniz Igan

December 2020

IMF Working Papers describe research in progress by the author(s) and are published to elicit comments and to encourage debate. The views expressed in IMF Working Papers are those of the author(s) and do not necessarily represent the views of the IMF, its Executive Board, or IMF management.

\begin{abstract}
Sovereign debt crises coincide with deep recessions. I propose a model of sovereign debt that rationalizes large contractions in economic activity via an aggregate-demand amplification mechanism. The mechanism also sheds new light on the response of consumption to sovereign risk, which I document in the context of the Eurozone crisis. By explicitly separating the decisions of households and the government, I examine the interaction between sovereign risk and precautionary savings. When a default is likely, households anticipate its negative consequences and cut consumption for self-insurance reasons. Such shortages in aggregate spending worsen economic conditions through nominal wage rigidities and boost default incentives, restarting the vicious cycle. I calibrate the model to Spain in the 2000s and find that about half of the output contraction is caused by default risk. More generally, sovereign risk exacerbates volatility in consumption over time and across agents, creating large and unequal welfare costs even if default does not materialize.

JEL Classification Numbers: E2, F3, G2
\end{abstract}

Keywords: Sovereign risk, default, heterogeneous agents, precautionary motives, aggregate demand Author's E-Mail Address: froldan@imf.org 


\section{CONTENTS}

$\begin{array}{ll}\text { Introduction } & 5\end{array}$

2 Motivating Evidence $\quad 10$

3 Minimal Models $\quad 12$

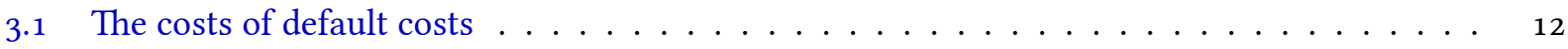

3.2 Propensities to consume and the anticipation of redistribution $\ldots \ldots \ldots \ldots$

4 Quantitative Model $\quad 16$

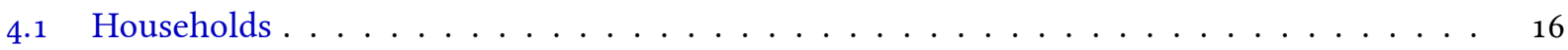

4.2 Relative prices and the real exchange rate $\ldots \ldots \ldots \ldots \ldots$

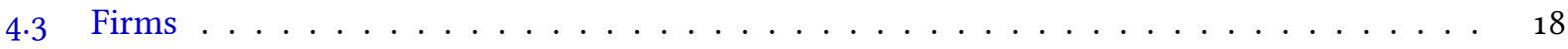

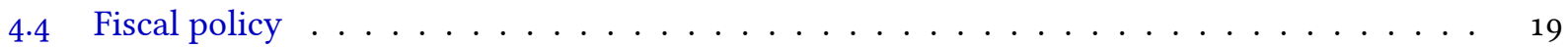

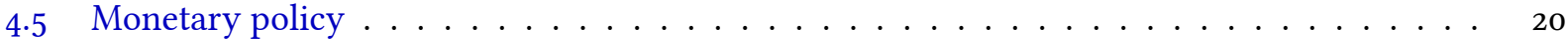

4.6 Foreign borrowing and the external sector $\ldots \ldots \ldots \ldots$

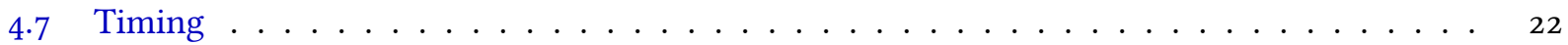

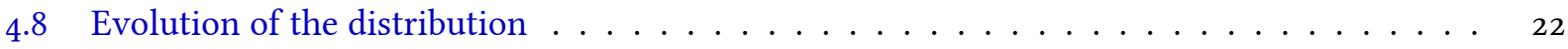

5 Equilibrium $\quad 23$

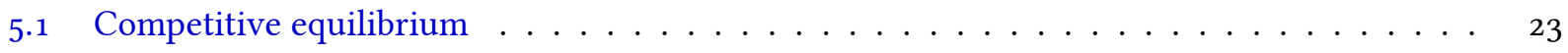

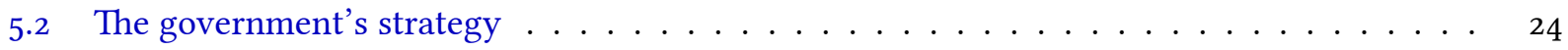

5.3 Euler equations and coupon payments $\ldots \ldots \ldots \ldots \ldots \ldots \ldots$

5.4 The household's reaction to sovereign risk $\ldots \ldots \ldots \ldots \ldots \ldots$

5.5 Wage rigidities and aggregate demand $\ldots \ldots \ldots \ldots \ldots$

6 Calibration $\quad 29$

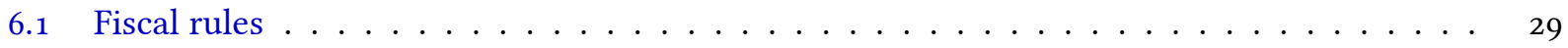

6.2 Model parameters . . . . . . . . . . . . . . . . . . . . . 29

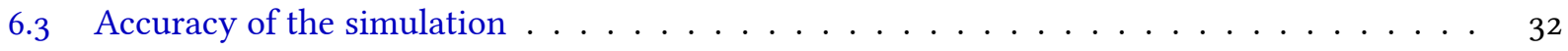


7.1 Government policy . . . . . . . . . . . . . . . . . 33

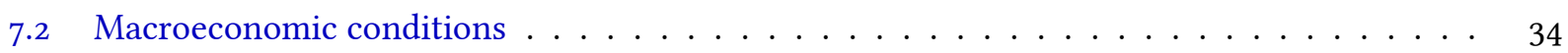

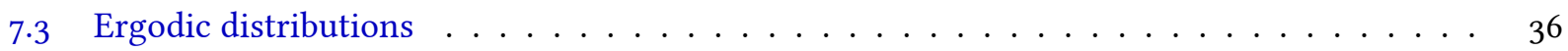

8 Crises $\quad 36$

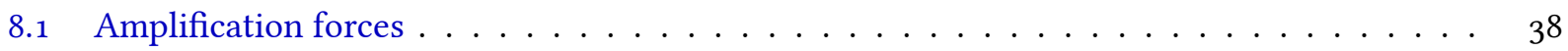

8.2 The distributional impact of sovereign risk $\ldots \ldots \ldots \ldots \ldots$

9 Concluding Remarks $\quad 4 \mathbf{4 1}$

$\begin{array}{ll}\text { A Appendix: Solution Details } & 45\end{array}$

A.1 The household's problem . . . . . . . . . . . . . . . . 45

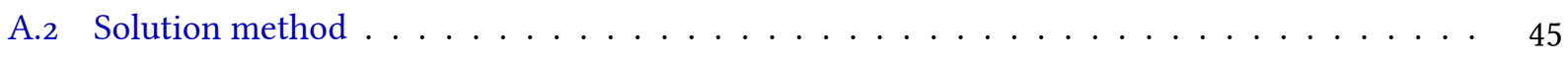

A.3 More model results $\ldots \ldots \ldots \ldots \ldots \ldots \ldots \ldots$

$\begin{array}{ll}\text { B Appendix: Evidence } & 47\end{array}$

$\begin{array}{ll}\text { C Appendix: Data sources } & 51\end{array}$ 


\section{INTRODUCTION $^{1}$}

Sovereign debt crises coincide with pronounced output contractions. During the Eurozone crisis, when spreads increased steeply for European countries, Spanish output fell by about $10 \%$ of its 2008 peak. While Spain did not ultimately default on its debts, unemployment doubled. The drop in private consumption was steeper than output, by up to $15 \%$ of the pre-crisis maximum. The resulting increase in the aggregate saving rate was not unique to the Spanish experience. I document that increases in sovereign spreads are associated with declines in output accompanied by larger declines in consumption for EU countries during the crisis.

In this paper I propose a model of sovereign debt that rationalizes these large output and consumption contractions in response to sovereign risk. The mechanism relies on the interaction between two wellunderstood features that have so far been studied separately: default risk and the precautionary savings motive of households. When economic conditions worsen and sovereign default becomes more likely, households anticipate its negative consequences. Each of them finds it optimal to cut consumption in favor of higher savings, leading to low aggregate spending. As wages are downwardly rigid, a recession follows. Thus, the model generates a vicious cycle of high spreads causing demand shortages, causing further increases in debt and spreads. This aggregate-demand doom loop amplifies underlying shocks to create deep recessions when sovereign risk emerges. Even if default does not materialize, its possibility endogenously exacerbates the volatility of consumption and output, creating large welfare costs of sovereign risk. I calibrate the model to Spain's debt crisis and use it to quantify the importance of this amplification mechanism.

The welfare costs of sovereign risk I emphasize yield a clear policy implication: debt crises should be resolved quickly. The model illustrates how prolonged periods of heightened sovereign risk carry costs in terms of output and employment through the feedback loop between spreads and demand. Swift resolution mechanisms that avoid delays and the uncertainty associated with them could enable significant welfare gains.

Domestic demand conditions are typically overlooked in the sovereign debt literature. Most studies assume either households that are effectively in financial autarky or one-sector small open economy models

\footnotetext{
${ }^{1}$ I owe an unsustainable debt of gratitude to my advisors Ricardo Lagos, Thomas Philippon, and Tom Sargent for their generous guidance and plentiful wisdom. This paper supersedes an earlier version entitled 'Aggregate Demand and Sovereign Debt Crises.' For insightful comments and discussions I wish to thank Nicolás Aragón, Yan Bai, Marcos Chamon, Gabriela Cugat, Mark Gertler, Simon Gilchrist, Nils Gornemann, Victoria Gregory, Martín Guzmán, Daniel Heymann, Deniz Igan, Rumen Kostadinov, Julián Kozlowski, Juan Morelli, Gastón Navarro, Ignacio Presno, Francisco Roch, Horacio Sapriza, César Sosa-Padilla, as well as seminar participants at the St. Louis Fed, YES 2018, the Fed Board, NYU Stern, Banco Central de Chile, PUC-Rio, the New York Fed, Carlos III, Midwest Macro Meetings 2019, EEA 2020, Ashoka, and PUC-Chile. Part of this research was conducted under the hospitality of the International Finance division at the Federal Reserve Board. The views expressed herein are my own and should not be attributed to the IMF, its Executive Board, or its management. All remaining errors are mine.
} 
in which domestic demand is irrelevant as all production can be exported. As a result, it cannot account for the role of households' savings decisions in the unfolding of a crisis. When households and the government are explicitly taken as separate actors, their interactions can create crisis events in which aggregate spending reacts to the anticipation of the government's actions differently than if those decisions were made in a coordinated way. In the canonical model, output and spreads are correlated because recessions increase default incentives: given debt prices, the presence of sovereign risk does not affect the economy unless a default actually happens.

To investigate the interaction between precautionary motives and sovereign risk, I consider a small open economy in which heterogeneous households, subject to uninsurable idiosyncratic income risk, can save as well as choose their exposure to government debt. This Bewley setup results in distributions of wealth and exposures to sovereign risk that interact with the government's decision to repay its debts. Rigidities in nominal wage setting combined with a currency peg (the model's representation of the Euro) create an aggregate-demand externality that transmits insufficient spending into increases in unemployment and contractions in output (Schmitt-Grohé and Uribe, 2016).

In the model, when the government defaults, it bears a cost in terms of lost TFP and exclusion from capital markets, as is common in the literature. In addition to this effect, as some of the debt is held domestically, defaults redistribute wealth.

Section 3 makes use of stylized models to lay out how these two consequences of sovereign defaults affect precautionary motives. The first model emphasizes the effect of TFP costs of default. While their impact on the government's incentives is well-understood, they also create volatility in future income when considered from an individual household's point of view. This boosts precautionary motives and, while a planner would also be affected by this extra volatility, households fail to internalize the demand externality present in the model and cut consumption by more. The second model emphasizes the redistribution of wealth caused by sovereign defaults. It clarifies the role played by the marginal propensities to consume (MPC) of different agents with respect to transfers at different time horizons. The key to this second model is that agents who have larger MPCs out of current income tend to have smaller MPCs out of future income. This means that the anticipation of a transfer may have the opposite effect on aggregate demand than the actual transfer.

In the quantitative model, both of these effects drive the behavior of the economy when spreads increase. Their strength, however, is modulated by the state of the economy, notably the endogenous distributions of wealth and exposures to sovereign risk. The potential redistribution in case of default also varies over time, as defaults transfer from bondholders (including foreigners), who receive lower payments, to domestic households, who face lower taxes. The effective transfer each agent expects to receive is determined by the distributions of wealth and exposures along with the (fixed, exogenous) distribution of the tax burden. 
The government's decision to repay its debts takes into account distributional considerations. When it chooses between default and repayment, the government understands the redistribution that defaults bring about. In line with both the literature and the data, the model implies higher sovereign risk when debt is higher and when productivity is lower. But default incentives are also heightened when the distribution of wealth is more unequal (Ferriere, 2016; Deng, 2020) as well as when the private sector is poorer as a whole.

To quantitatively assess the welfare costs of sovereign risk, I calibrate the model to Spain in the 2000 . In addition to standard targets in the sovereign debt literature, I target the wealth-to-GDP ratio as well as the Gini index for wealth and the share of sovereign debt held domestically. I then simulate a long time-series from the calibrated model and isolate episodes of crisis. I define a crisis in the simulated data as an episode that resembles the Spanish experience of 2010-2013: no default accompanied by elevated sovereign spreads. The model, solved without the possibility of sovereign default but simulated with the same underlying shocks, features much milder recessions at the times in which the benchmark model is in crisis: about $30 \%$ of the output contraction during a typical simulated crisis can be directly attributed to the presence of sovereign risk. The behavior of consumption is also markedly different across models during these crisis episodes: while the benchmark model broadly matches the Spanish experience, the model without default exhibits much more smoothing in aggregate consumption.

The comparison with the model without default reveals that most of the volatility in aggregate consumption is caused by sovereign risk. The extra volatility is costly for the economy: on average, households would give up about $4.2 \%$ of permanent consumption to make defaults impossible. The default episodes themselves are extremely costly: at the height of a crisis, moving to a world without the possibility of default is worth about $12 \%$ of permanent consumption to the average household.

The heterogeneous-agents setup also allows me to examine the impact of sovereign risk across the wealth distribution. I find substantial heterogeneity in welfare costs of sovereign risk, which range between $5 \%$ of permanent consumption for the bottom $10 \%$ of the wealth distribution to $3.7 \%$ for the top $10 \%$.

A common argument during debt crises is that a lack of 'confidence' causes aggregate demand to fall short of levels consistent with full employment. This paper addresses this argument as a rational, although inefficient, response to the evolution of fundamentals in the economy. Without commitment to future policies, the government's ex-post default incentives act during crises as large-scale increases in uncertainty (Bloom, 2009). From a broader perspective, the amplification I emphasize helps explain why emerging economies exhibit high volatility of consumption relative to output 'as if' they were subject to trend shocks, especially on the downside (Aguiar and Gopinath, 2007).

The model ties the presence of sovereign risk to a high volatility of consumption relative to output. Standard models of sovereign debt share this feature on the surface: the real interest rate is countercyclical, which makes consumption procyclical. However, these models refer to the government's borrowing rate, which is not necessarily the one faced by households. While private borrowing rates do tend to correlate 
with the rate on government securities, this is typically not true of saving rates (see Martínez Pagés, 2017; Arnold and de Vries-van Ewijk, 2014, and Figure 22). In the 2000s, Spanish households held about 94\% of GDP in net worth (Figure 23), which makes the claim that only borrowing rates matter problematic.

Finally, the setup with heterogeneous households allows for a clean separation of the debts and assets of the government and the private sector. In canonical models of sovereign debt, allowing households access to risk-free borrowing and saving unravels the equilibrium. The reason is simple: if the government has access to lump-sum taxes and the representative household can commit to repay loans, then the government can use its tax policy to effectively have the household borrow on its behalf at the risk-free rate. This has naturally led researchers to study models in which the private sector's financial choices are constrained. An alternative is to constrain the tax instruments at the government's disposal. In my model, even though the government can collect lump-sum taxes and agents can save, it cannot make those taxes agent-specific. This provides a natural constraint on the government's ability to sidestep its lack of commitment.

Discussion of the Literature This paper relates to several strands of literature. I build on canonical models of sovereign debt (Eaton and Gersovitz, 1981; Aguiar and Gopinath, 2006; Arellano, 2008) by considering a benevolent government borrowing without commitment from international creditors. Recent papers have emphasized internal costs of sovereign default. Mendoza and Yue (2012) argue that domestic firms lose access to some imported inputs after a default, which reduces aggregate productivity. From these papers I take the shape and size of default costs, which are exogenous in my model.

Others such as Gennaioli, Martin, and Rossi (2014), Pérez (2018), and Mallucci (2015) argue that the presence of domestic debt creates default costs through the disruption of financial intermediation. These papers assume households are able to save and provide deposits to the financial sector. However, because they use one-sector models in which the law of one price holds, they effectively abstract from the aggregate demand effects I emphasize.

I build on models in which nominal rigidities in wage setting combined with an exchange rate peg create an aggregate demand externality (Schmitt-Grohé and Uribe, 2016, and a large literature). Anzoategui (2020) combines wage rigidities and default risk to estimate counterfactual series for Spain had it not imposed austerity measures in the crisis. The tradeoff emphasized in that paper is that austerity depresses aggregate demand but endogenously decreases the probability of a debt crisis. Bianchi, Ottonello, and Presno (2016) also think about fiscal multipliers in the presence of sovereign risk and they characterize the optimal policy in the presence of wage rigidities, where the government can affect the real exchange rate via the relative demand for traded and nontraded goods. Both papers abstract from the precautionary effects that are at the core of my argument by assuming that domestic households are unable to save.

In a similar line to mine, Arellano, Bai, and Mihalache (2020) consider a New Keynesian small open economy model with an aggregate demand externality where the government chooses its fiscal and default 
policy. They focus on the case when the Central Bank follows a Taylor rule, the currency floats freely and the economy undergoes a real devaluation at the time of default. These differences in assumptions affect their conclusions in interesting and complementary ways to the one presented here.

Some studies, like Bocola (2016); Arellano, Bai, and Bocola (2017); Arellano, Bai, and Mihalache (2018); Balke (2017), explicitly consider anticipation effects in investment from sovereign risk, endogeneizing the correlation of interest rates for government borrowing and investment or working capital loans assumed by Neumeyer and Perri (2005). In the first two papers, when the probability of default is high, banks attach a higher value to safe assets. They lose appetite for risk and charge firms a higher interest rate. Investment drops which depresses growth in a complementary way to the one explored here. Because it works through the supply side of the economy, this mechanism cannot by itself account for the savings pattern of households in the crisis. Moreover, this mechanism requires that banks be unable to raise equity, which is correct in the short run but less likely as time passes. I take the opposite stand that the financial sector acts as a veil for the nonfinancial private sector. This also highlights inequality within the private sector as a driver of the output response to sovereign risk.

Philippon and Roldán (2018) study the optimal sovereign deleveraging plan in a related but more stylized setting. They find that the direct contractionary impact of austerity negates the gains from aggressive deleveraging in the crisis and argue for a gradual plan. Romei (2015) considers the distributional impact of different speeds of fiscal consolidation in the absence of aggregate demand effects. In a flexible-price model, Cuadra, Sánchez, and Sapriza (2010) argue that governments constrained by their own lack of commitment to future actions find it optimal to follow procyclical fiscal policies.

Part of how sovereign risk affects demand is because of redistribution. In this sense, I build on models such as Eggertsson and Krugman (2012), Auclert (2017), or Korinek and Simsek (2016), where shocks contract demand because they redistribute from high-MPC to low-MPC agents. This paper features this idea prominently, except that the timing of transfers reverses the identities of low- and high-MPC agents.

Finally, this paper also relates to studies in which sovereign debt policy responds to distributional concerns, as has been emphasized since Woodford (1990). While distributional concerns are featured in its objective function, the government in my model does not issue debt to help domestic agents, who can save in the international risk-free bond, with their self-insurance (as in Aiyagari and McGrattan, 1998; Shin, 2006). D’Erasmo and Mendoza (2016) build a heterogeneous-agents model of sovereign default and find that levels of debt like those of present day Spain suggest a government with a bias towards favoring its creditors. Ferriere (2016), Ferriere and Navarro (2017), and Deng (2020) argue for a positive link between progressive taxation on the one hand and incentives to repay sovereign debt and fiscal multipliers on the other. Guembel and Sussman (2009) and Andreasen, Sandleris, and van der Ghote (2011) study political economy considerations in sovereign debt policy, while Dovis, Golosov, and Shourideh (2016) find that, in an overlapping-generations economy, the tension between the ex-ante desire to promote savings and the 
ex-post temptation to redistribute by taxing capital can lead to 'populist cycles' of austerity and external debt-financed expansions.

Layout The remainder of the paper is organized as follows. Section 2 presents some motivating evidence. Section 3 starts by building some intuition in two highly stylized settings. Then, Section 4 describes the quantitative model while Section 5 defines the equilibrium and clarifies the inner workings of the model. Section 6 discusses the calibration and Section 7 summarizes results from the model solution. Section 8 focuses on crises and presents the main results. Finally, Section 9 concludes.

\section{Motivating Evidence}

Figure 1 plots total GDP and households' consumption for Spain in the 20oos. To show each series in as raw a form as possible, I plot them relative to the value at the start of 2008. Output and consumption strongly contract during the crisis years. Moreover, consumption contracts more than output as the crisis unfolds. Figures 25 and 26 in the Appendix reinforce this point by showing that the same pattern appears in HP-detrended data and that it corresponds to an increase in the trade balance. Peak to trough, the declines in output and consumption are of about $10 \%$ and $15 \%$. These numbers can be misleading as they include the effect of the Global Financial Crisis and the Spanish housing bust. Comparing the trough of the crisis to early 2011 to isolate the effect of sovereign risk as much as possible, the output and consumption contractions are of the order of $5 \%$ and $9 \%$.

\section{Output and Consumption for Spain}

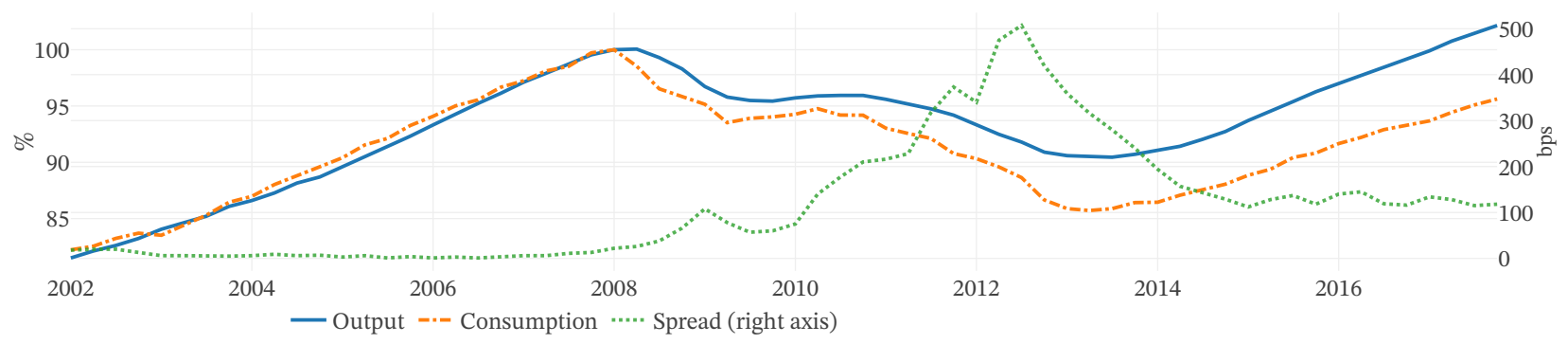

Figure 1: Spanish OUtput AND Consumption in the 2000S

Table 8 in the Appendix replicates the volatility calculations from Aguiar and Gopinath (2007) using the Eurozone crisis data. For Spain, Italy, and Portugal (and the Netherlands), the volatility of consumption is greater than the volatility of output, and the ratio of those volatilities is larger now than it was in Aguiar and Gopinath's data from the late 2 oth century. On the other hand, for countries that were mostly unscathed by the crisis (such as Austria, Belgium, Denmark, and Finland), the relative volatility of consumption remains low. 
The case of Spain in the Eurozone crisis is of particular interest, as a default did not actually happen even though full repayment of government was uncertain during the period: Figure 1 reveals that a 10-year Spanish government bond paid a significant interest rate spread over a comparable German Bund. Figure 20 shows that measures of slack in the Spanish economy increase significantly during the crisis in what looks like two phases, consistent with the private deleveraging followed by sudden stop interpretation of Martin and Philippon (2017). The two phases are also noticeable as two separate instances of output contraction in Figure 1. Finally, Figure 21 in the Appendix contains results from a Eurostat survey of Spanish firms who are asked about the reasons why they produce what they do and not more. The proportion of firms reporting 'demand' as their main limiting factor is elevated during the crisis.

Finally, the patterns emphasized for Spain in Figure 1 are not a particular feature of the Spanish experience. Using quarterly data for 11 European countries between 2010 and 2013, I consider equations of the type

$$
Q_{j t}=\beta \text { Spread }_{j t}+\gamma X_{j t}+\mu_{j}+\delta_{t}+\varepsilon_{j t}
$$

for $Q_{j t}=\log Y_{j t}, \log C_{j t}$, where the $X_{j t}$ 's are controls and $\mu_{j}$ and $\delta_{t}$ are country and time fixed effects.

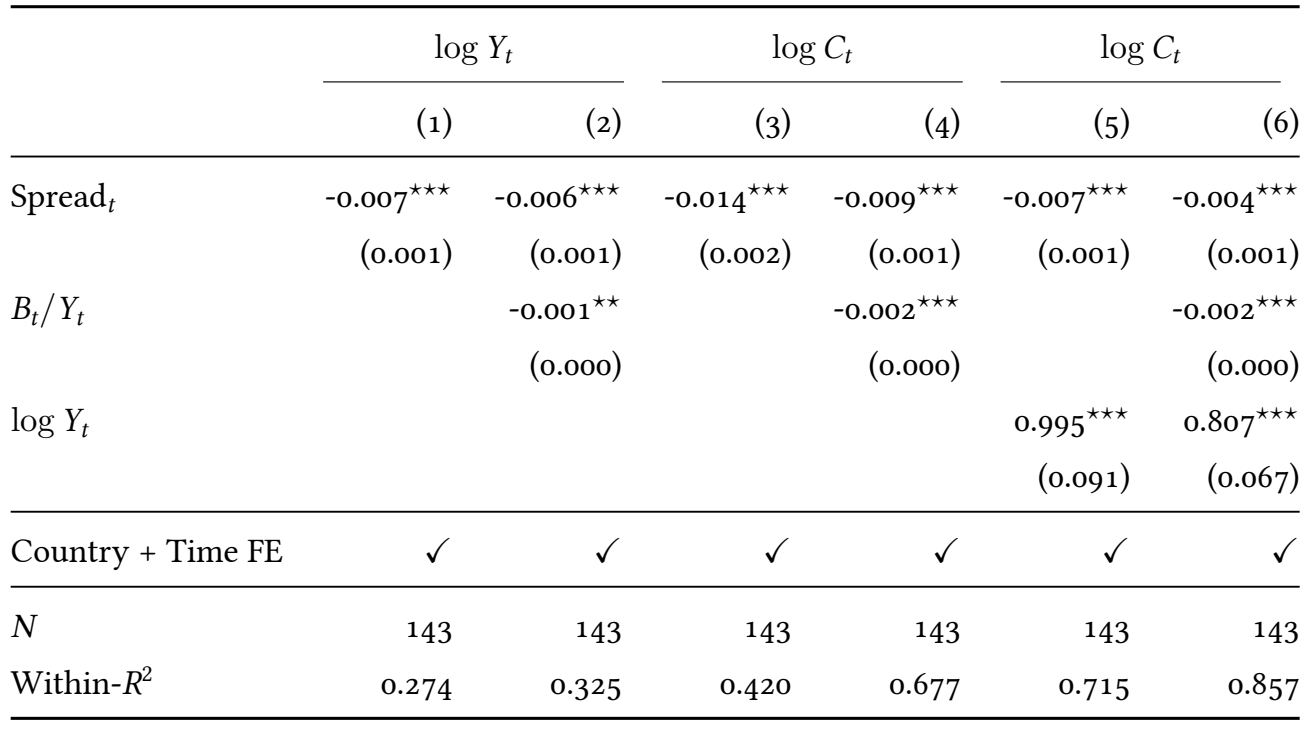

Standard errors in parentheses. ${ }^{\star \star \star} p<0.01,{ }^{\star \star} p<0.05,{ }^{\star} p<0.1$.

\section{Table 1: Correlation of Spreads And Macroeconomic Outcomes}

Table 1 summarizes the estimation of (1). It shows that countries that saw larger increases in their spreads also saw larger contractions in output and consumption. The coefficients in the first four columns mean that a typical country experiencing the average increase in spreads (about 2oobps) saw a fall in output of between $1.2 \%$ and $1.4 \%$ and a fall in consumption of between $1.8 \%$ and $2.7 \%$. The two last columns informally test the hypothesis that the consumption response is larger than the output response, by controlling for output in the consumption regression. The coefficients are negative and significant, documenting the larger relative contraction in consumption for countries that saw larger increases in spreads. 


\section{Minimal Models}

I begin by considering two highly stylized environments, designed to distill the core of the argument. In the first model, expectations of income losses in case of default depress aggregate demand in the present. The second model shows how the redistribution induced by defaults when there are domestic holdings of sovereign debt also contributes to the contraction in demand. Both the effects emphasized in this section will be important drivers of the quantitative results in the rest of the paper.

\subsection{The costs of default costs}

Consider a small open economy with a representative agent who lives for two periods and receives stochastic endowments $y_{t}^{T}$ of a tradable good. The representative agent can save an amount $s_{1} \geq 0$ in the first period, which would be available for consumption in the second period. In the second period, some legacy debt $d$ becomes due to foreigners. If the government fails to repay, output falls by a factor of $\Delta$. The representative agent's consumption is

$$
c_{2}= \begin{cases}y_{2}-d+s_{1} & \text { if the government repays } \\ y_{2}(1-\Delta)+s_{1} & \text { if the government defaults }\end{cases}
$$

Assuming that the government maximizes the utility of the representative agent, it follows that there is default if and only if $y_{2}<d / \Delta$.

In the first period, the small open economy also produces a nontraded good with labor, subject to wage rigidities, according to the production function

$$
y_{1}^{N}=F\left(h_{1}\right)=h_{1}^{\alpha}
$$

where $\alpha<1$. The first-order condition for the firm's labor demand is

$$
h=\left(\frac{\alpha p_{N}}{w}\right)^{\frac{1}{1-\alpha}}
$$

Suppose also that the representative agent has standard CES preferences across traded and nontraded goods with elasticity of substitution $\eta$ and relative weight $\varpi$ for the nontraded good, so that

$$
c_{N}=\left(\frac{\emptyset}{1-\Phi} \frac{p_{T}}{p_{N}}\right)^{\frac{1}{1+\eta}} c_{T}
$$

where $p_{T}, p_{N}$ are the prices of traded and nontraded goods and $c_{T}, c_{N}$ are quantities consumed.

This first-order condition for consumption of traded and nontraded goods in the first period, combined with the firm's labor demand, implies that

$$
h=\mathcal{H}\left(c_{T}, w\right)=\left(\frac{\varrho}{1-\varpi} \frac{\alpha}{w}\right)^{\frac{1}{1+\alpha \eta}} c_{T}^{1+\eta}
$$


I assume nominal rigidities in the form of a wage floor $\bar{w}$, so that either $h=1$ and the wage satisfies (2) or, when the constraint binds, $w=\bar{w}$ and $h=\mathcal{H}\left(c_{T}, \bar{w}\right)$. Crucially, equilibrium employment is an increasing function of traded consumption in the constrained regime.

A planner who could direct the representative agent's choices in the first period would solve

$$
\begin{aligned}
& \max _{s_{1}} u\left(c_{T}, F(h)\right)+\beta \mathbb{E}\left[u\left(\max \left\{y_{2}-d, y_{2}(1-\Delta)\right\}+s_{1}\right)\right] \\
& \text { subject to } c_{T}+\frac{s_{1}}{1+r}=y_{1} \\
& h=\min \left\{1, \mathcal{H}\left(c_{T}, \bar{w}\right)\right\}
\end{aligned}
$$

In a descentralized equilibrium the household would solve the same problem, except it would take as given employment $h$. In equilibrium, however, employment would still satisfy the second constraint. The representative agent does not internalize that more demand for (traded) goods also means more labor demand.

The first-order condition for problem (3) is the planner's Euler equation

$$
u_{T}^{\prime}\left(c_{T}, F(h)\right)+\mathcal{H}_{c}^{\prime}\left(c_{T}, \bar{w}\right) \mu=\beta(1+r) \mathbb{E}\left[u^{\prime}\left(y_{2}+s-\min \left\{d, y_{2} \Delta\right\}\right)\right]
$$

where $\mu=u_{N}^{\prime}\left(c_{T}, F(h)\right) F^{\prime}(h)$ is the multiplier on the wage floor constraint. The default cost $\Delta$ and the debt level $d$ both enter this Euler equation the same way, increasing the marginal value of consumption in the second period. An increase in either of them therefore boosts precautionary savings in the first period. The planner, however, understands that more savings in the first period may decrease employment, when $\mathcal{H}_{c}^{\prime}\left(c_{T}, \bar{w}\right)>0$. Figure 2 summarizes the effect of $d$ and $\Delta$ on the equilibrium, both for the planner and in the decentralized case.

Which interest rate? If the planner can repurchase the debt instead of saving at the risk-free rate, the Euler equation becomes

$$
u_{T}^{\prime}\left(c_{T}, F(h)\right)+\mathcal{H}_{c}^{\prime}\left(c_{T}, \bar{w}\right) \mu=\beta \frac{1}{q\left(d-s_{1}, \Delta\right)+s_{1} q_{d}\left(d-s_{1}, \Delta\right)} \mathbb{E}\left[u^{\prime}\left(y_{2}+s_{1}-\min \left\{d, y_{2} \Delta\right\}\right)\right]
$$

where $q(d, \Delta)=\frac{1-\mathbb{P}\left(y_{2}<d / \Delta\right)}{1+r}$ is the price of debt in the first period and $q_{d}(d, \Delta)$ is its derivative with respect to indebtedness. In this case increases in $\Delta$ (or $d$ ) still push up the relevant marginal utility of future consumption. However, increases in $\Delta$ also push up the debt price, cancelling part of the effect. Increases in initial debt $d$, on the other hand, have a larger impact in this case as they push down the debt price, magnifying the effect. In any case, for a given change in expected marginal utility, the reaction of current consumption will be muted, as repurchases of debt push up the price, resulting in a smaller required change in savings. The question becomes how much can current savings affect the total stock of debt and future default incentives. An exhaustive discussion of these effects, along with their implications for the ex-ante optimal default cost, therefore, requires a less stylized setting and is therefore left as an open question. 

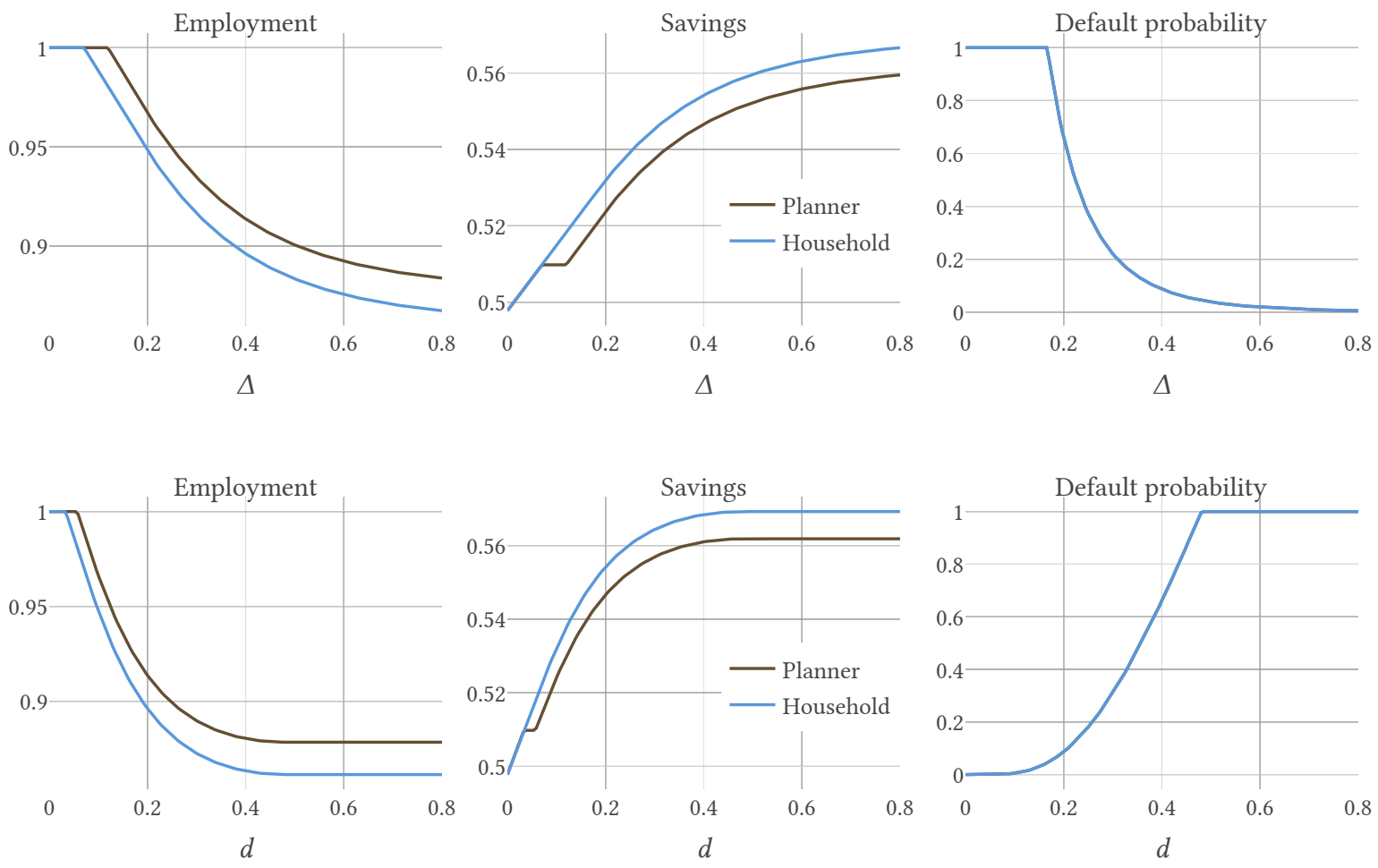

Figure 2: ANTicipation OF TFP costs OF DEFAult

\subsection{Propensities to consume and the anticipation of redistribution}

Consider now a closed economy populated by a measure $\chi$ of hand-to-mouth agents and $1-\chi$ of 'savers,' each endowed with one unit of labor in each period. The only good is produced with labor with constant returns to scale, $y=h$.

In the second period prices are fully flexible but with probability $\pi$ there is a transfer $k$ from savers to hand-to-mouth agents. Consumptions in the second period are

$$
\left(c_{1}^{s}, c_{1}^{h}\right)= \begin{cases}(1-k, 1+k) & \text { with probability } \pi \\ (1,1) & \text { with probability } 1-\pi\end{cases}
$$

In the first period, all prices are fixed. The wage rate is $w$, the price of the good is normalized to 1 . Savers trade risk-free securities in zero net supply at a real interest rate $r$. Consumption of savers satisfies the Euler equation

$$
u^{\prime}\left(c_{1}^{s}\right)=\beta(1+r)\left[\pi u^{\prime}(1-k)+(1-\pi) u^{\prime}(1)\right]
$$

Assuming CARA utility with absolute risk aversion $\gamma$ (as in Philippon and Roldán, 2018), the first-period 
consumption of savers is

$$
c_{1}^{s}=1-\frac{1}{\gamma} \log (\beta(1+r))-\frac{1}{\gamma} \log \left(1-\pi+\pi e^{\gamma k}\right)
$$

The size of the potential transfer $k$ unambiguously reduces savers' consumption. The size of the effect is also increasing in the probability $\pi$. The effect of the risk aversion parameter is a little more complicated. It both amplifies the effect ( $\gamma$ appears multiplying $k$ inside the exponential) and dampens it. This is because $\gamma$ is both risk aversion and the inverse of the intertemporal elasticity of substitution. Risk aversion makes savers dislike differences in consumption across states in the second period and induces more savings. But when $\gamma$ increases, consumption in both periods becomes less substitutable, which reduces the incentive to save (it also reduces the incentive to save in response to interest rates).

Hand-to-mouth agents' consumption, on the other hand, is entirely dictated by their budget constraint in the first period. In the simplest case, we have

$$
c_{1}^{h}=w h
$$

For markets to clear, output must equal the total demand of both types, $y=\chi c_{1}^{h}+(1-\chi) c_{1}^{s}$, or, using that $y=h$,

$$
y=\frac{1-\chi}{1-\chi w} c_{1}^{s}
$$

To the extent that there is unemployment, the presence of hand-to-mouth agents makes output a multiple of the consumption of savers. Figure 3 shows output in percent deviations from a no-transfer benchmark. It illustrates how the expected redistribution depresses output in the first period. Demand of savers (and hence output) is decreasing in both the probability of the transfer $\pi$ and its expected size $k$.

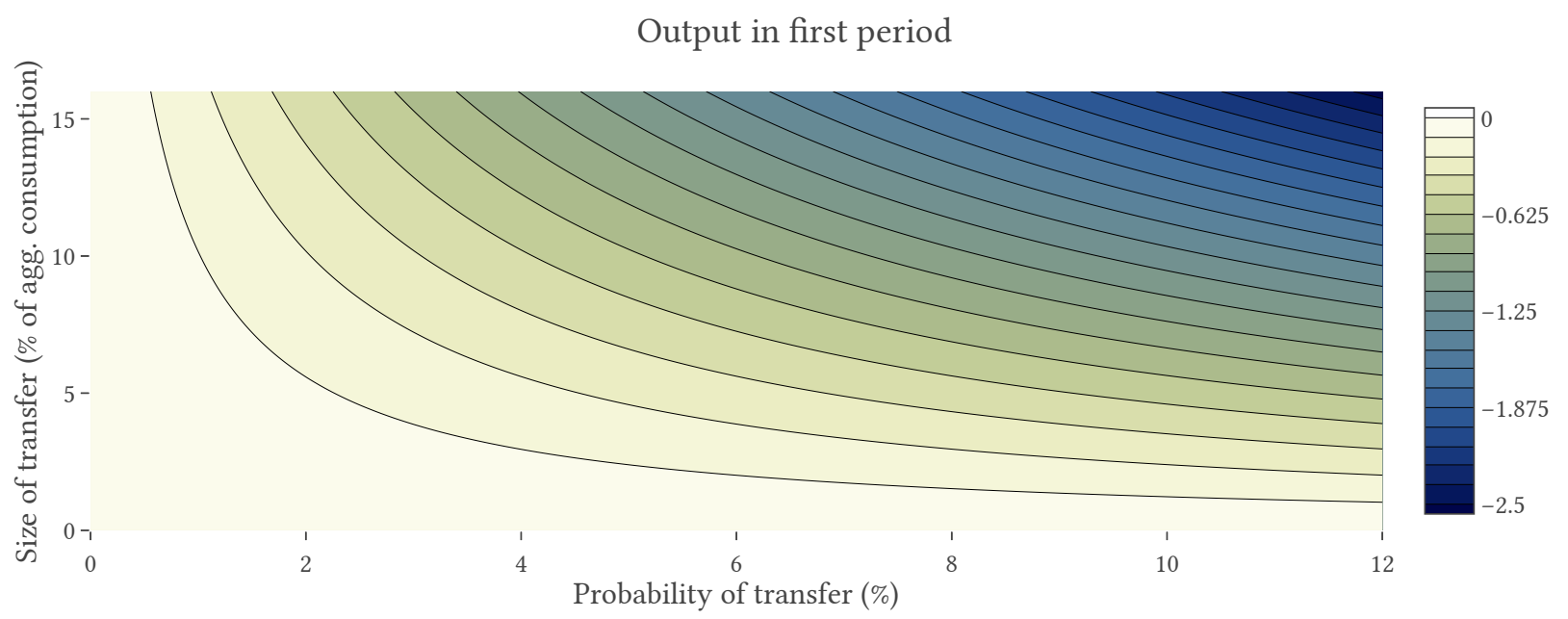

Figure 3: ANTICIPATION OF REDISTRIBUtion IN CASE OF DEFAULT

This model illustrates how a potential transfer from unconstrained to constrained agents has the opposite effect on the economy than an actual transfer from unconstrained to constrained agents. In this 
extreme example, hand-to-mouth agents have an MPC of 1 out of current income but of 0 out of future income. Savers, on the other hand, are not affected by the timing of income: their MPC is smaller out of current income but remains positive as the transfer considered takes place further into the future.

Finally, suppose that the government attempted to reduce its stock of debt, as in the extension of the first model. Assume that, at least at the margin, it does so by collecting lump-sum taxes equal across types of agents. On the one hand, reducing the default probability might counteract some of the savers' precautionary behavior. But it would also directly affect the hand-to-mouth agents, whose MPC out of this type of transfers is 1 . This type of austerity-induced redistribution that hurts aggregate demand, which also features in the quantitative model below, is a well-understood effect (see for example Auclert, 2017, Anzoategui, 2020, or Bianchi, Ottonello, and Presno, 2016, who also include transfers to foreigners whose MPC is zero as far as the domestic economy is concerned).

\section{Quantitative Model}

The effects illustrated in Section 3 depend on a variety of endogenous objects: the amount of debt outstanding when spreads increase, its distribution across foreign and domestic agents (as well as among domestic agents), the distribution of MPCs for various current and future transfers. The model presented here aims to provide the necessary elements for a quantitative evaluation of the Spanish crisis.

I consider a small open economy populated by a continuum of heterogeneous households and firms that produce tradable and nontradable goods. A government runs an exogenous, estimated fiscal rule for spending and debt issuance but chooses between default and repayment with discretion. There are incomplete markets and only two assets are traded: a one-period, risk-free private security and a longterm, noncontingent, defaultable government bond.

\subsection{Households}

There is a continuum of heterogeneous households who differ in the realization of an uninsurable idiosyncratic shock to their effective labor supply, $\varepsilon$, as well as in their asset holdings. Let $a$ and $b$ denote holdings of the risk-free asset and of government debt, respectively. Households are limited in their ability to hold negative positions in these assets: it is impossible to short the government, and there is an ad-hoc lower bound $\bar{a}$ on the risk-free asset. Respecting these restrictions, both assets trade at prices $q^{h}$ and $q^{g}$.

Households value the consumption of traded and nontraded goods according to a CES aggregator

$$
c=\left[\omega^{\frac{1}{\eta}} c_{N}^{\frac{\eta-1}{\eta}}+(1-\Phi)^{\frac{1}{\eta}} c_{T}^{\frac{\eta-1}{\eta}}\right]^{\frac{\eta}{\eta-1}}
$$

where $\eta$ is the elasticity of substition among the two goods. I assume an inelastic labor supply. Households 
have Epstein-Zin preferences over streams of consumption represented by the value function

$$
v_{t}=\left((1-\beta) c_{t}^{\frac{\psi-1}{\psi}}+\beta \mathbb{E}_{t}\left[v_{t+1}{ }^{1-\gamma}\right]^{\frac{\psi-1}{\psi(1-\gamma)}}\right)^{\frac{\psi}{\psi-1}}
$$

where $\beta$ is the discount factor, $\gamma$ is the coefficient of risk-aversion and $\psi$ is the inverse elasticity of intertemporal substitution.

In period $t$, households observe the aggregate state of the economy $\mathrm{S}_{t}=\left(B_{t}, \lambda_{t}, \xi_{t}, \zeta_{t}, z_{t}\right)$, comprised of total government debt outstanding $B_{t}$, the current distribution of households over their idiosyncratic states $\lambda_{t}$, the current value of a shock to sovereign spreads $\xi_{t}$, the current state of the country in international credit markets $\zeta_{t}$, and the current level of a productivity shock $z_{t}$. In equilibrium, this information is enough to recover the relative price of nontraded goods $p_{N}\left(\mathbf{S}_{t}\right)$ and the current wage rate $w\left(\mathbf{S}_{t}\right)$, as well as the price of government debt $q^{g}\left(\mathbf{S}_{t}\right)$, lump-sum taxes $T\left(\mathbf{S}_{t}\right)$, firms' profits $\Pi\left(\mathrm{S}_{t}\right)$, and the price of consumption (CPI)

$$
p_{C}=p_{C}\left(p_{N}\right)=\left[\omega p_{N}^{1-\eta}+(1-\varpi)\right]^{\frac{1}{1-\eta}}
$$

where the price of traded goods is normalized to $p_{T}=1$.

Government debt is a long-term asset which promises a geometrically-decaying coupon payment denominated in the traded good, as in Leland (1998) and Chatterjee and Eyigungor (2012). While the government is not in default, holders of debt purchased $t$ periods ago receive $\kappa(1-\rho)^{t-1}$. This standard setup makes one unit of debt a perfect substitute of $1-\rho$ units of debt issued in the following period. When the government defaults, a haircut $\hbar$ is applied to all outstanding debt and coupon payments are suspended until the government regains market access.

The household's idiosyncratic states are the current level of its labor productivity $\varepsilon$ as well as the total value of its asset portfolio $\omega_{t}=a_{t-1}^{\prime}+R_{t-1, t}^{b} b_{t-1}^{\prime}$. I adopt the convention that the risk-free asset pays one unit of the traded good while the government bond yields $R_{t-1, t}^{b}$. Let $\mathbf{s}=(\omega, \varepsilon)$ denote the idiosyncratic state vector. Individual labor productivity follows an $\mathrm{AR}(1)$ process in $\log$ so $\log \varepsilon_{t+1}=\rho_{\varepsilon} \log \varepsilon_{t}+\sigma_{\varepsilon} v_{t+1}^{\varepsilon}$, where $v_{t}^{\varepsilon} \stackrel{\text { iid }}{\sim} \mathcal{N}(0,1)$.

Labor supply is inelastic. Because of nominal rigidities (see below), there can be rationing in the labor market when labor demand falls short of supply. In that case, I assume that households are rationed proportionally so that everyone works the same amount of hours. These assumptions mean that a household with current shock $\varepsilon$ receives (pre-tax) labor income equal to $y^{L}(\mathbf{s}, \mathbf{S})=w(\mathbf{S}) L(\mathbf{S}) \varepsilon$ at wage $w$ and employment $L$ in state $\mathrm{S}$, of which a fraction $\tau$ is paid to the government as labor income taxes.

Households also receive income from ownership of the firms. I assume that this income is rebated lump-sum in proportion to the current value of the shock $\varepsilon$. Because the integral of $\varepsilon$ is normalized to 1 , households receive income $y^{\Pi}(\mathbf{s}, \mathbf{S})=\Pi(\mathbf{S}) \varepsilon$. 
The household's problem (4) summarizes the discussion above.

$$
\begin{aligned}
& v(\omega, \varepsilon, \mathbf{S})=\max _{a^{\prime}, b^{\prime}, c}\left((1-\beta) c^{\frac{\psi-1}{\psi}}+\beta \mathbb{E}\left[\left(v\left(a^{\prime}+R_{b}\left(\mathbf{S}, \mathbf{S}^{\prime}\right) b^{\prime}, \varepsilon^{\prime}, \mathbf{S}^{\prime}\right)\right)^{1-\gamma} \mid \omega, \varepsilon, \mathbf{S}\right]^{\frac{\psi-1}{\psi(1-\gamma)}}\right)^{\frac{\psi}{\psi-1}} \\
& \text { subject to } p_{C}\left(p_{N}(\mathbf{S})\right) c+q^{h}(\mathbf{S}) a^{\prime}+q^{g}(\mathbf{S}) b^{\prime}=\omega+\ell(\mathbf{S}) \varepsilon-T(\mathbf{S}) \\
& \ell(\mathbf{S})=w(\mathbf{S}) L(\mathbf{S})(1-\tau)+\Pi(\mathbf{S}) \\
& R_{b}\left(\mathbf{S}, \mathbf{S}^{\prime}\right)=1_{\left(\zeta^{\prime}=1\right)} \kappa+(1-\rho)\left(1-\hbar 1_{(\zeta=1) \cap\left(\zeta^{\prime} \neq 1\right)}\right) q^{g}\left(\mathbf{S}^{\prime}\right) \\
& b^{\prime} \geq 0 ; \quad a^{\prime} \geq \bar{a} \\
& \mathbf{S}^{\prime}=\Psi\left(\mathbf{S}, \zeta^{\prime}, z^{\prime}, \zeta^{\prime}\right)
\end{aligned}
$$

This problem is affected by the presence of sovereign risk in at least three distinct ways. An increase in default risk depresses expected future income, generates capital losses through movements in realized $R_{b}$, and worsens the savings technology by making expected $R_{b}$ more negatively correlated with future income. Section 5.4 discusses these effects in detail.

The solution to the household's problem consists of policy function $\varphi_{a}, \varphi_{b}, \varphi_{c}: s \times \mathcal{S} \rightarrow \mathbb{R}$. It is important to notice that the value function $v(\mathbf{s}, \mathrm{S})$ describes a household after the government's default decision.

\subsection{Relative prices and the real exchange rate}

I now turn to the determination of the relative price of the nontraded good (the real exchange rate). Because of the homotheticity of CES demand, each household consumes both goods in the same proportions. The first-order condition for the composition of consumption, summing over all agents, then reads

$$
p_{N}(\mathbf{S})=\frac{\omega^{1 / \eta}}{(1-\omega)^{1 / \eta}}\left(\frac{C_{T}(\mathbf{S})}{C_{N}(\mathbf{S})}\right)^{\frac{1}{\eta}}
$$

\subsection{Firms}

There are two types of firms that produce traded and nontraded goods. Their technologies are concave in labor and are given by

$$
\begin{aligned}
& Y_{N t}=f_{N}\left(z_{t}, \zeta_{t}\right) L_{N t}^{\alpha_{N}} \\
& Y_{T t}=f_{T}\left(z_{t}, \zeta_{t}\right) L_{T t}^{\alpha_{T}}
\end{aligned}
$$

The functions $f_{i}$ for $i \in\{N, T\}$ describe productivity in both sectors. TFP depends on the productivity shock $z_{t}$ and is reduced when the economy is in default. As a benchmark, I consider the case where the 
shock $z_{t}$ only affects the production of traded goods

$$
\begin{aligned}
& f_{N}(z, \zeta)=1-\Delta 1_{(\zeta \neq 1)} \\
& f_{T}(z, \zeta)=z\left(1-\Delta 1_{(\zeta \neq 1)}\right)
\end{aligned}
$$

where $\Delta$ is the output cost of default and $\zeta=1$ denotes good standing in international markets.

In equilibrium, firms in both sectors must pay the same wage. However, because of nominal rigidities, the wage $w_{t}$ cannot fall below $\bar{w}$, as in Bianchi, Ottonello, and Presno (2016). When the constraint does not bind, the economy operates at full employment; otherwise, workers are rationed. I discuss this way of introducing nominal rigidities in more detail in Section 5.5.

\subsection{Fiscal policy}

The government's policy determines four actions: whether to repay its current debt obligations in full, how much new debt to issue, the amount of government spending, and the level of lump-sum transfers it gives to households.

The government's budget constraint (8) equates resources from (net) debt issuance and labor income taxes to expenditures given by coupon payments, government spending, and lump-sum transfers

$$
\underbrace{q^{g}\left(\mathbf{S}_{t}\right)}_{\text {debt price }} \underbrace{\left(B^{\prime}\left(\mathbf{S}_{t}\right)-(1-\rho) B\left(\mathbf{S}_{t}\right)\right)}_{\text {new debt issued }}+\underbrace{\tau w\left(\mathbf{S}_{t}\right) L\left(\mathbf{S}_{t}\right)}_{\text {income tax }}=\underbrace{\kappa 1_{(\zeta=1)} B\left(\mathbf{S}_{t}\right)}_{\text {coupon }}+\underbrace{g\left(\mathbf{S}_{t}\right)}_{\text {spending }}-\underbrace{T\left(\mathbf{S}_{t}\right)}_{\text {lump-sum }}
$$

This budget constraint means that, given $q^{g}\left(\mathrm{~S}_{t}\right)$, the government's choice of transfers $T\left(\mathrm{~S}_{t}\right)$ can be obtained as a residual from its issuance $B^{\prime}(\mathbf{S})$ and spending $g(\mathbf{S})$ policies.

When the government is in default (denoted by $\zeta=0$ ), coupon payments are interrupted. However, holders can still trade it in secondary markets. Defaulted debt is still valuable as the government recovers access to markets with constant probability $\theta$. While in default, new debt cannot be issued (even if it would command a positive price), which restricts $B^{\prime}\left(\mathbf{S}_{t}\right)=B\left(\mathbf{S}_{t}\right)$ in default states.

I assume that the government follows exogenous fiscal rules to determine consumption $g$ and debt issuances $B^{\prime}$. These are allowed to be a function of the whole state vector, and I estimate them to match observed correlations with key business cycles statistics (see Section 6). Finally, I assume that the government spends a constant fraction $\vartheta_{N}$ of its expenditures on the nontraded good.

Defaults and the evolution of debt The repayment strategy of the government $h^{\prime}\left(\mathbf{S}_{t}, \xi_{t+1}, z_{t+1}\right)$ specifies a repayment probability in each state of the following period. The government makes its default choice in period $t+1$ having observed the exogenous states $\left(\xi_{t+1}, z_{t+1}\right)$ and understanding which aggregate states $\mathrm{S}_{t+1}$ result from repayment and from default. The government also receives an iid preference shock $\xi^{\text {def }}$ orthogonal to all other variables, which plays the role of smoothing out the policy for numerical tractability. 
The mean of the shock also helps me match the average spread by controlling the unconditional default frequency, as discussed in Section 5.2.

If there is a default in period $t+1$, a haircut of $\hbar$ applies to the debt of the government. This means that $B\left(\mathbf{S}_{t+1}\right)=(1-\hbar) B^{\prime}\left(\mathbf{S}_{t}\right)$, whereas $B\left(\mathbf{S}_{t+1}\right)=B^{\prime}\left(\mathbf{S}_{t}\right)$ otherwise. When in default, there is a constant probability $\theta$ of reentering financial markets.

The budget constraint (8) captures a particular tradeoff. When resources from tax collections and debt issuance are low (for instance, when spreads are high), the government chooses between default or low lump-sum transfers. In this context, one could interpret the second option as a regressive austerity plan.

\subsection{Monetary policy}

The small open economy defends a pegged exchange rate. Everywhere in the model, this assumption amounts to a normalization of the (constant) price of nontraded goods $p_{T} \equiv 1$. Importantly, I assume that the economy does not abandon the peg upon default, as Na, Schmitt-Grohé, Uribe, and Yue (2018) argue is a relevant case.

Relaxing my assumption to have devaluations accompany defaults would not be innocuous. It would certainly reduce the aggregate income losses from default by allowing real wages to fall. On the other hand, it would create wealth effects from the currency of denomination of contracts and assets that households own. The first consequence can be captured in this model by making the bound on wages depend on the default state $\zeta$. However, addressing the second, probably more interesting consequence requires a rich model of currency choice and is beyond the scope of this paper.

\subsection{Foreign borrowing and the external sector}

I assume a large quantity of foreigners who have access to funds at a fixed international risk-free rate $r^{\star}$. Immediately, this implies that

$$
q^{h}(\mathbf{S})=\frac{1}{1+r^{\star}}
$$

Furthermore, if foreigners hold the government's debt in state S, then by no arbitrage it has to be the case that

$$
q^{g}(\mathbf{S})=\frac{1}{1+r^{\star}} \mathbb{E}[\underbrace{1_{\left(\zeta^{\prime}=1\right)}\left(1-\xi^{\prime}\right) \kappa}_{\text {coupon }}+\underbrace{\left(1-\rho 1_{\left(\zeta^{\prime}=1\right)}\right)}_{\text {depreciation }} \underbrace{\left(1-\hbar 1_{\left(\zeta=1 \cap \zeta^{\prime} \neq 1\right)}\right)}_{\text {potential haircut }} \underbrace{q^{g}\left(\mathbf{S}^{\prime}\right)}_{\text {resale price }} \mid \mathrm{S}]
$$

which reflects that debt is a claim to coupon payments while there is no default, that a default entails the haircut $\hbar$, and that the unmatured fraction $(1-\rho)$ of the bond can be resold in secondary markets. With respect to the coupon payments, I assume that foreigners price debt as if the coupon payment was $\left(1-\xi^{\prime}\right) \kappa$ 
where the stochastic process for $\xi$ is constrained to remain within the interval $(0,1)$. This assumption artificially depresses the price of government debt in order to match the home bias in holdings (see Section 5.3 for a discussion).

If the government was already in default at state $S_{t}$, equation (10) specializes to

$$
q^{g}(\mathbf{S} \mid \zeta \neq 1)=\frac{1}{1+r^{\star}}\left(\theta \mathbb{E}\left[1-\xi^{\prime} \mid \mathbf{S}\right] \kappa+(1-\rho \theta) \mathbb{E}\left[q^{g}\left(\mathbf{S}^{\prime}\right) \mid \mathbf{S}\right]\right)
$$

as the government reenters international markets with constant hazard $\theta$ and it cannot default again while in the default state.

Equation (10) only holds when foreigners hold some of the debt. I assume that, as in the data, domestic demand for government debt always falls short of the total amount outstanding. I then check in simulation that this is the case.

I measure the implicit (promised) interest rate $r^{b}$ on a government bond as the discount rate that equalizes the promised payments to the debt price, or

$$
q^{g}(\mathbf{S})=\sum_{s=0}^{\infty} \frac{\kappa(1-\rho)^{s}}{\left(1+r^{b}(\mathbf{S})\right)^{s+1}}
$$

which comes down to $r^{b}(\mathbf{S})=\frac{\kappa}{q^{g}(\mathbf{S})}-\rho$. The spread on government debt is then the difference between $r^{b}$ and the risk-free rate $r^{\star}$. Because of the normalization that $\kappa=r^{\star}+\rho$, the spread can be easily computed from the debt price as $\operatorname{spr}(\mathbf{S})=\kappa\left(\frac{1}{q^{g}(\mathbf{S})}-1\right)$

When the small open economy is indebted with the rest of world, its consolidated intertemporal budget constraint states that the value of debt obligations must equal the expected discounted value of trade surpluses. If $A$ denotes the total amount of risk-free debt and $A^{f}, A^{h}$ that in hands of foreigners and domestic agents, respectively, and the same convention applies to government debt $B$, net foreign inflows are given by

$$
\mathrm{NFI}_{t}=\underbrace{q_{t}^{h} A_{t+1}^{f}+q_{t}^{g}\left(B_{t}^{\prime f}-(1-\rho) B_{t}^{f}\right)}_{\text {Capital inflows }}-\underbrace{\left(\kappa B_{t}^{f}+A_{t}^{f}\right)}_{\text {Capital outflows }}
$$

where resources flow into the small open economy when domestic agents borrow from foreigners and when foreigners purchase debt. On the other hand, resources flow out when the government makes coupon payments to foreigners and when domestic agents repays their debts.

Because the distribution $\lambda$ does not distinguish holdings of both assets separately, neither $A_{t}$ nor its components are a function of the state variables $S_{t}$. However, some manipulation allows to recast (12) in terms of flows as

$$
\begin{aligned}
\mathrm{NFI}_{t} & =q_{t}^{g} B_{t}^{\prime f}-\left(A_{t}^{f}+\left(\kappa+(1-\rho) q_{t}^{g}\right) B_{t}^{f}\right)+q_{t}^{h} A_{t+1}^{f} \\
& =\int\left(\omega-q_{t}^{h} \varphi_{a}-q_{t}^{g} \varphi_{b}\right) d \lambda_{t}-\kappa B_{t}+q_{t}^{g}\left(B_{t}^{\prime}-(1-\rho) B_{t}\right)
\end{aligned}
$$


where government debt held by foreigners equals $B_{t}^{\prime f}=B_{t}^{\prime}-\int \varphi_{b} d \lambda_{t}$, private debt held by foreigners equals $A_{t+1}^{f}=-\int \varphi_{a} d \lambda_{t}$, and $\int \omega d \lambda_{t}=A_{t}^{h}+\left(\kappa+(1-\rho) q_{t}^{g}\right) B_{t}^{h}$.

Finally, market clearing requires that

$$
Y_{N t}=C_{N t}+\frac{\vartheta_{N}}{p_{N t}} G_{t} \quad \text { and } \quad Y_{T t}+\mathrm{NFI}_{t}=C_{T t}+\left(1-\vartheta_{N}\right) G_{t}
$$

as net foreign inflows must equal the trade deficit.

\subsection{Timing}

Figure 4 summarizes the unfolding of events within a period. The past state is carried from the previous period. Then nature chooses the current level of TFP and risk premia. Observing these, the government decides its repayment if it is not in default already. If the country was already in default, then nature chooses whether there is reentry to financial markets. Only then do foreign lenders set asset prices. At this point the distribution of wealth across households is determined. The government then implements its issuance and transfer policies. Finally, firms choose employment and prices, the households make their consumption and savings choices, and the period ends.

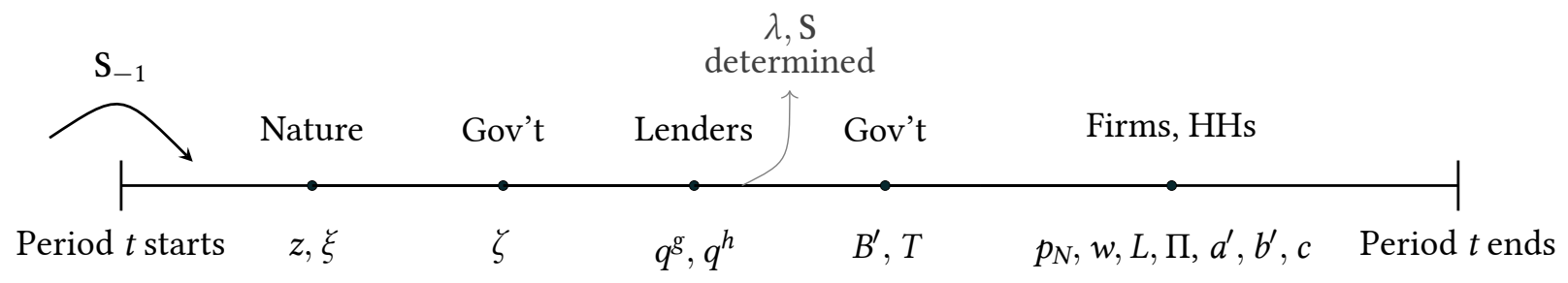

Figure 4: Timeline

\subsection{Evolution of the distribution}

Before defining the equilibrium, I discuss a particular assumption that allows me to solve the model parsimoniously. In the exposition above, the state vector $\mathrm{S}$ contains the whole distribution of agents across their idiosyncratic states, which is an infinitely-dimensional object. As is usual in heterogeneous-agents models, I proceed by solving for a bounded rationality equilibrium where agents only have limited knowledge of the distribution $\lambda$.

Specifically, I assume that agents believe the distribution of wealth and individual labor productivity to be jointly lognormal with

$$
\left(\begin{array}{c}
\omega_{t} \\
\varepsilon_{t}
\end{array}\right) \sim \log \mathcal{N}\left(\left[\begin{array}{c}
\mu_{t} \\
0
\end{array}\right],\left[\begin{array}{ll}
\sigma_{t} & \rho_{t} \\
\rho_{t} & \sigma_{\varepsilon}
\end{array}\right]\right)
$$


where as of this writing, I further assume that $\rho_{t}=0$. As discussed below in Section 6.3, this extra approximation turns out not to hurt the accuracy of the algorithm. $\mu_{t}$ and $\sigma_{t}$, however, vary over time and become state variables.

This assumption allows me to summarize $\lambda_{t}$ with $\left(\mu_{t}, \sigma_{t}, \rho_{t}\right)$. As for the law of motion of the distribution, the household's policy functions need not imply that $\lambda_{t+1}$ is exactly lognormal even if $\lambda_{t}$ is. This is the key place where the approximation is taken, as I assume laws of motion for the distribution parameters.

Two approximations happen at once. The first is that I only solve for the equilibrium on a subset (the lognormal distributions) of the infinite dimensional space of all possible distributions. Bounded rationality happens along the second approximation: whenever the policy functions imply a distribution that is not lognormal for the following period, I project it back onto the $(\mu, \sigma, \rho)$ space by making all agents in the model expect a lognormal distribution with the same mean and variance than the one implied by the policies.

Given all functions of the state (including the households' policy functions) and the current distribution, substituting $\lambda_{t}$ for the corresponding lognormal in (15) yields a system for the joint evolution of the parameters of the distribution as well as the price of debt (which depends on the future distribution through the government's default incentives)

$$
\left\{\begin{aligned}
R_{b}\left(\mathbf{S}_{t+1}\right) & =1_{\left(\zeta_{t+1}=1\right)} \kappa+(1-\rho) q^{g}\left(\mathbf{S}_{t+1}\right) \\
\int \omega d \lambda_{t+1} & =\int \varphi_{a}\left(\mathbf{s}_{t}, \mathbf{S}_{t}\right)+R_{b}\left(\mathbf{S}_{t+1}\right) \varphi_{b}\left(\mathbf{s}_{t}, \mathbf{S}_{t}\right) d \lambda_{t} \\
\int \omega^{2} d \lambda_{t+1} & =\int\left[\varphi_{a}\left(\mathbf{s}_{t}, \mathbf{S}_{t}\right)+R_{b}\left(\mathbf{S}_{t+1}\right) \varphi_{b}\left(\mathbf{s}_{t}, \mathbf{S}_{t}\right)\right]^{2} d \lambda_{t} \\
\int \omega \varepsilon d \lambda_{t+1} & =\int\left[\varphi_{a}\left(\mathbf{s}_{t}, \mathbf{S}_{t}\right)+R_{b}\left(\mathbf{S}_{t+1}\right) \varphi_{b}\left(\mathbf{s}_{t}, \mathbf{S}_{t}\right)\right] \varepsilon^{\prime} f\left(\varepsilon_{t}, \varepsilon^{\prime}\right) d \lambda_{t}
\end{aligned}\right.
$$

These approximations allow me to solve for the equilibrium of the model without the usual simulation step. Instead, I check in simulation that the agents' forecasting rule accurately predicts the dynamics of relevant variables. Section 6.3 discusses the accuracy of my procedure.

\section{EQUiLIBRium}

\subsection{Competitive equilibrium}

Definition Given government policies $h^{\prime}\left(\mathbf{S}, \xi^{\prime}, z^{\prime}\right), B^{\prime}(\mathbf{S})$, and $g(\mathbf{S})$, a competitive equilibrium consists of value and policy functions $\left\{v, \varphi_{a}, \varphi_{b}, \varphi_{c}\right\}(\mathbf{s}, \mathbf{S})$, aggregates $L_{T}(\mathbf{S}), L_{N}(\mathbf{S}), \Pi(\mathbf{S}), Y_{N}(\mathbf{S}), Y_{T}(\mathbf{S})$, prices $p_{C}(\mathbf{S})$, $p_{N}(\mathbf{S}), w(\mathbf{S}), q^{g}(\mathbf{S}), q^{h}(\mathbf{S})$, taxes $T(\mathbf{S})$ and laws of motion for the distribution parameters $\left\{\mu^{\prime}, \sigma^{\prime}\right\}\left(\mathbf{S}, \xi^{\prime}, z^{\prime}, \zeta^{\prime}\right)$ such that

- The policy functions solve the household's problem (4) given prices, aggregates, and the law of motion 
for the distribution.

- The relative price of nontraded goods $p_{N}(\mathbf{S})$ satisfies the intratemporal first-order condition (5).

- The aggregates $L_{T}(\mathbf{S}), L_{N}(\mathbf{S})$ maximize the firms profits given prices $w(\mathbf{S}), p_{N}(\mathbf{S})$ and the quantities produced $Y_{N}(\mathbf{S}), Y_{T}(\mathbf{S})$ satisfy the production functions $(6,7)$.

- The lump-sum taxes $T(\mathrm{~S})$ satisfy the government's budget constraint (8).

- Asset prices $q^{h}(\mathbf{S})$ and $q^{g}(\mathbf{S})$ satisfy the no-arbitrage conditions $(9,10)$.

- Market clearing

1. in traded and nontraded goods (13).

2. in labor: either $w(\mathbf{S})=\bar{w}$ or $L_{T}(\mathbf{S})+L_{N}(\mathbf{S})=\int \varepsilon d \lambda_{\mathbf{S}}$.

- The laws of motion for the distribution parameters satisfy the consistency requirement (15).

\subsection{The government's strategy}

The government's objective is to maximize current welfare in the economy. I assume that it places equal weights on every agent. In each state and without commitment, the government maximizes

$$
\mathcal{W}\left(\mathbf{S}, h^{\prime}\right)=\int v(\mathbf{s}, \mathbf{S}) d \lambda_{\mathbf{S}}(\mathbf{s})+1_{(\zeta=1)}\left(\mu_{g}+\sigma_{g} \xi^{d e f}\right)
$$

where $\xi^{\text {def }} \stackrel{\text { iid }}{\sim} \mathcal{N}(0,1)$ is a preference shock that serves the numerical purpose of smoothing the default policy. The mean of the shock $\mu_{g}$ helps me discipline the average default frequency in the model as, in contrast to standard models of sovereign default, here the discount factor and the risk aversion parameter are disciplined by moments of the private wealth distribution. The government is subject to equilibrium conditions and its budget constraint, where the notation $\lambda_{\mathrm{s}}$ emphasizes that the distribution is a part of the aggregate state S. Importantly, the value function and the distribution correspond to the competitive equilibrium that results under the policy $h^{\prime}$.

A policy $h^{\prime}$ for repayment is a part of an equilibrium if, at each $\left(\mathrm{S}, z^{\prime}\right)$, the probability of repayment satisfies

$$
h^{\prime}\left(\mathbf{S}, z^{\prime}\right)=\mathbb{P}(\mu_{g}+\sigma_{g} \xi^{\text {def }} \leq \underbrace{\mathcal{W}\left(\Psi\left(\mathrm{S}, \xi^{\prime}, z^{\prime}, \zeta^{\prime}=1\right), h^{\prime}\right)}_{\text {value under repayment }}-\underbrace{\mathcal{W}\left(\Psi\left(\mathrm{S}, \xi^{\prime}, z^{\prime}, \zeta^{\prime} \neq 1, h^{\prime}\right)\right)}_{\text {value under default }})
$$

where $\Psi\left(\mathrm{S}, \xi^{\prime}, z^{\prime}, \zeta^{\prime}\right)=\mathrm{S}^{\prime}$ is the state that ensues when $\left(\xi^{\prime}, z^{\prime}\right)$ are realized after $\mathrm{S}$ and the government chooses a default state $\zeta^{\prime}$. Equation (17) makes it clear that, after observing the realization of $\xi^{\prime}$ and $z^{\prime}$, the government understands which state $\mathrm{S}^{\prime}$ results if it decides to default or to repay. This includes the level of debt remaining to be paid as well as the distribution induced in each case. 
Condition (17) is a rational-expectations restriction: the policy that households, foreigners, and the current government expect of future governments, $h^{\prime}$, must coincide with the policy that the government would choose if allowed a deviation that did not alter future expectations. In other words, condition (17) insists that the policy $h^{\prime}$ be part of a Nash equilibrium. The restriction that all policies depend only on the current state $\mathrm{S}$ (and not on the whole history of play) further refines the solution concept to that of recursive equilibrium.

Appendix A.2 describes the computation of a solution in detail.

\subsection{Euler equations and coupon payments}

The Euler equation (18) determines a household's purchases of government bonds:

$$
q^{g}(\mathbf{S}) \geq \beta \mathbb{E}[\underbrace{R_{b}\left(\mathbf{S}, \mathbf{S}^{\prime}\right) \frac{p_{C}(\mathbf{S})}{p_{C}\left(\mathbf{S}^{\prime}\right)}}_{\text {real repayment }} \underbrace{\left(\frac{\varphi_{c}\left(\omega^{\prime}, \varepsilon^{\prime}, \mathbf{S}^{\prime}\right)}{\varphi_{c}(\omega, \varepsilon, \mathbf{S})}\right)^{-\frac{1}{\psi}}}_{\text {Stochastic discount factor }} \underbrace{\left(\frac{v\left(\omega^{\prime}, \varepsilon^{\prime}, \mathbf{S}^{\prime}\right)}{\mathbb{E}\left[v\left(\omega^{\prime}, \varepsilon^{\prime}, \mathbf{S}^{\prime}\right)^{1-\gamma} \mid \mathbf{S}\right]^{\frac{1}{1-\gamma}}}\right)^{\frac{1}{\psi}-\gamma}}_{\text {Intertemp. subs. }} \mid \mathbf{S}]
$$

with equality if the household is purchasing a positive amount of bonds.

Comparing this equation with the pricing equation (10), it is immediate to infer that if $\xi$ were equal to zero then the household would not buy too many government bonds. Being risk-averse, the household demands a risk premium to expose itself to the risk of the government. The shock $\xi$ plays the role of creating a risk premium in the return of the government bond when compared to the return of the risk-free asset. This allows the model to match the high proportion of sovereign debt held by domestic agents in the data. Moreover, introducing $\xi$ as a shock allows me to study the economy's response to increases in spreads that are not driven by changes in fundamentals of the domestic economy.

\subsection{The household's reaction to sovereign risk}

There are at least three main ways in which sovereign risk affects the household's problem (4). The first effect concerns the aggregate income losses that happen in case of default. Conditional on default, TFP drops by $\Delta$ is both sectors for a random amount of periods, which puts downward pressure on the marketclearing wage. If the constraint binds, unemployment increases. In any case, other things equal labor income $w(\mathbf{S}) L(\mathbf{S}) \varepsilon$ is lower in default than in repayment. In states with a higher default probability, the household consequently feels poorer and reduces consumption.

Figure 5 shows expected labor income (integrating out heterogeneity in $\varepsilon$ ) as a function of next period's TFP for default and repayment. Various panels condition on current levels of debt and the risk-premium 
shock $\xi$. Labor income is clearly increasing in TFP and higher in repayment than in default. Both the current level of government debt and the risk-premium shock tend to close the gap.

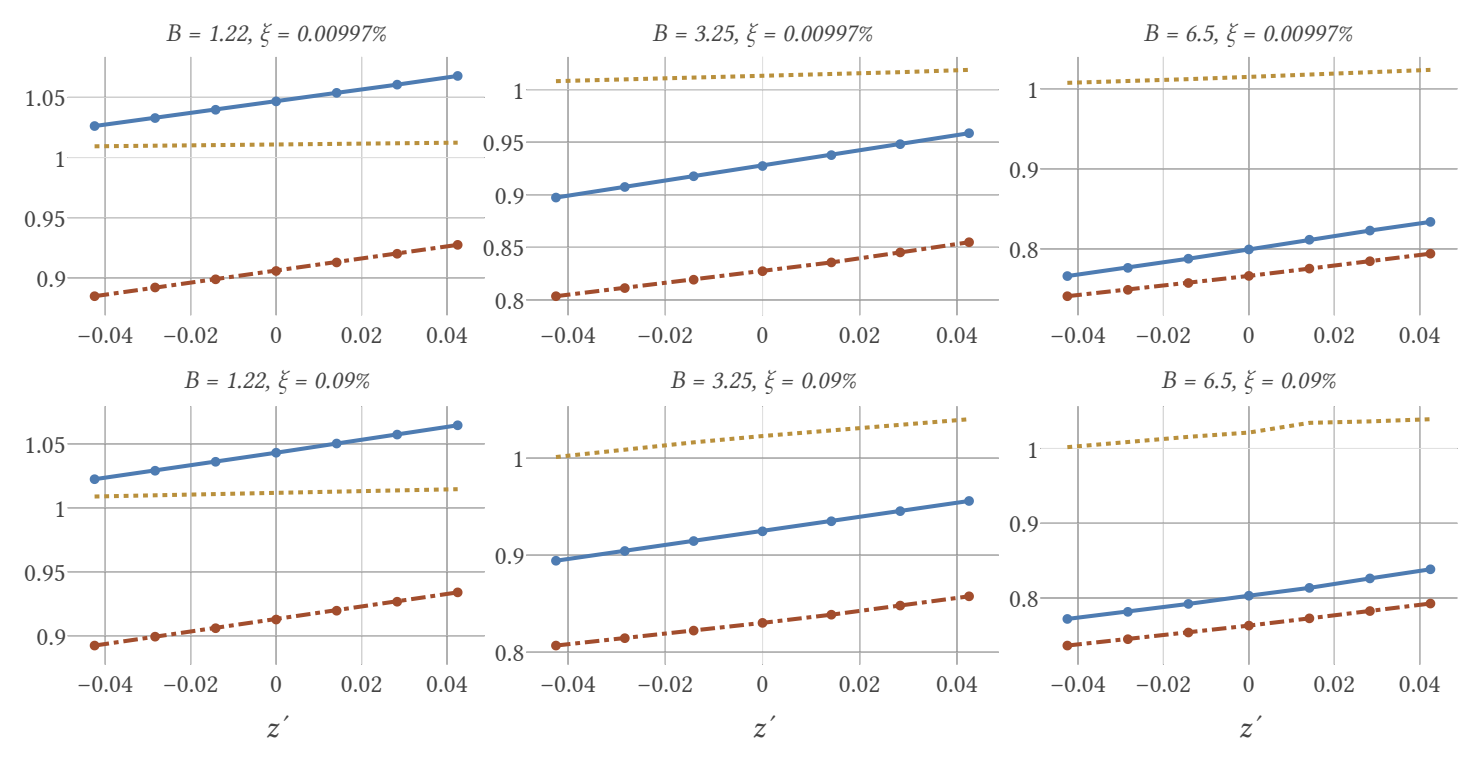

Figure 5: LABor InCOME AND Expected Returns

Note: Blue lines plot income in repayment, red dashed lines plot income in default, orange dotted lines plot the return of holding government debt

A second effect goes through the price of government bonds. $q^{g}(\mathbf{S})$ reflects the default probability and shocks that make it increase also decrease the resale value of bonds. Households who purchased these bonds in the past make an inmediate capital loss when $q^{g}$ drops. In the aggregate, a distributional effect shifts the wealth distribution to the left when the default probability increases. The strength of this channel depends critically on the proportion of bonds held by domestic agents, as well as in the level of inequality in domestic bondholdings. Figure 11 below shows the price of debt as function of the economy's state variables. Variables that predict future default risk have a significant effect on sovereign spreads.

Finally, the household cares about the insurance properties of the government bond. Sovereign risk makes those very different in normal times and in crisis times. Recall the return of a government bond

$$
R_{b}\left(\mathrm{~S}, \mathrm{~S}^{\prime}\right)=1_{\left(\zeta^{\prime}=1\right)} \kappa+(1-\rho)\left(1-\hbar 1_{(\zeta=1) \cap\left(\zeta^{\prime} \neq 1\right)}\right) q^{g}\left(\mathbf{S}^{\prime}\right)
$$

In normal times, the variance of $R_{b}$ is relatively low. Its variation comes mostly from variation in the future resale price $q^{g}\left(\mathbf{S}^{\prime}\right)$. However, as the default probability increases more and more of the variance of $R_{b}$ becomes driven by variation in the repayment probability. Moreover, repayment correlates with aggregate income as the government's incentives to default are stronger in bad times. Hence, the conditional covariance between the bond return and the stochastic discount factor of households tends to be larger in crises. This feature makes the bond a bad hedge always but an even worse one when spreads are high. 
Figure 5 shows realized bond returns in addition to labor income. Both the aggregate income losses and the savings technology effects are evident in the picture. The variance of returns, as well as its covariance with income, increases when default becomes more uncertain. When default is very unlikely (left panels) or very likely (right panels), next period's shocks do not influence the default probability (and hence return on holding the debt) very much. When debt is intermediate, holding it bears a very volatile return which also comoves significantly with income.

Who fears sovereign default? A robustness-based perspective The household's Euler equation offers insights into how sovereign risk affects different types of households. I calibrate the model with a unitary elasticity of intertemporal substitution. With this parameterization, households act 'as if' they had logarithmic preferences combined with concerns about model misspecification (Maenhout, 2004; Hansen and Sargent, 2001; Tallarini, 2000). In this reinterpretation, the risk aversion parameter maps into a robustness parameter. I define the subjective expectation, taken by an agent in state $(\mathbf{s}, \mathrm{S})$, of a random variable $X$ as

$$
\tilde{\mathbb{E}}[X \mid \mathbf{s}, \mathbf{S}]=\mathbb{E}\left[\frac{v\left(\omega^{\prime}, \varepsilon^{\prime}, \mathbf{S}^{\prime}\right)^{1-\gamma}}{\mathbb{E}\left[v\left(\omega^{\prime}, \varepsilon^{\prime}, \mathbf{S}^{\prime}\right)^{1-\gamma} \mid \mathbf{S}\right]} X \mid \mathbf{s}, \mathbf{S}\right]
$$

The subjective expectation twists expectations by attaching more weight to states in which the household's value function is lower. It overstates events feared by the household. Figure 6 shows the twisted probability of default for each household, computed setting $X$ to the indicator of a default in the next period in (19). The computation is conditional on a state of crisis. Figure 6 also shows the actual probability of default for comparison. Richer and higher-income households fear default, while poorer and low-income households fear the prolongation of the crisis.

Twisted default probabilities

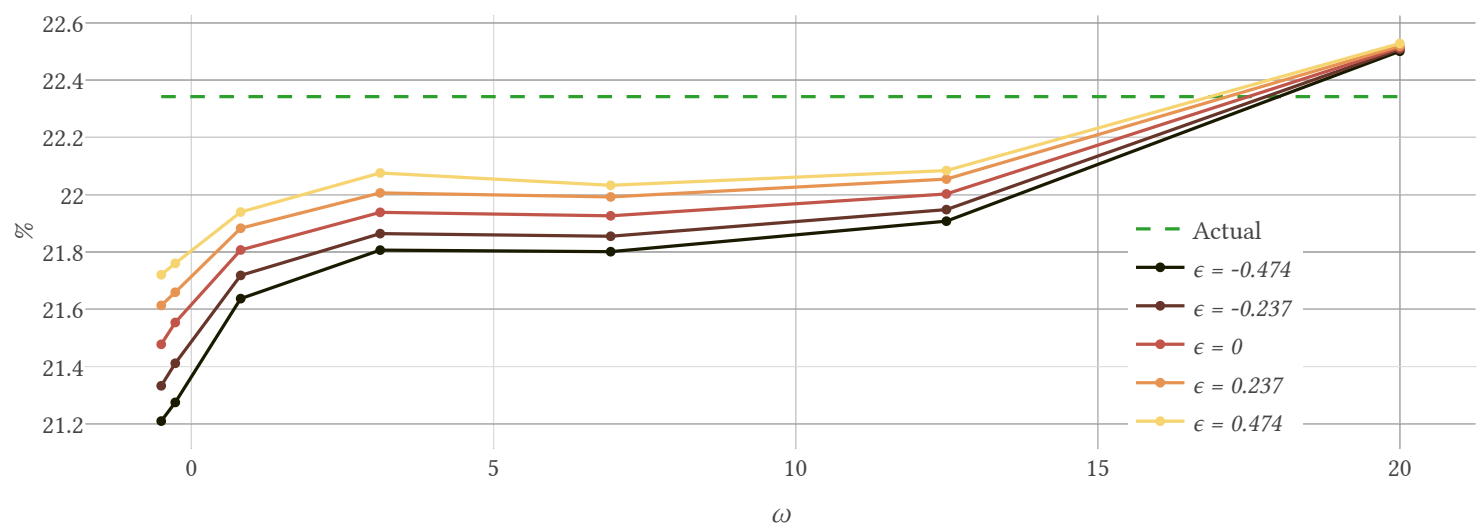

Figure 6: SubJective PRobabilities of Default 


\subsection{Wage rigidities and aggregate demand}

When sovereign risk increases, the demand for consumption is likely to fall. This feeds back to the rest of the economy mainly through the market for nontraded goods.

In the market for traded goods, firms can supply whatever quantities they produce at the international price. Therefore, for a given wage rate $w_{t}$ prevailing in the economy, traded goods-producing firms observe the current level of TFP and choose employment accordingly.

The market for nontraded goods features more action, which is summarized by its supply curve. To trace it out, suppose a decrease in the relative price of nontraded goods. According to their first-order condition (20), firms respond to this decrease by cutting down production.

$$
L_{N}^{d}=\left(\alpha_{N} \frac{p_{N}}{\max \{w, \bar{w}\}}\right)^{\frac{1}{1-\alpha_{N}}}
$$

When firms in the nontraded sector retract their production they expell workers. This pushes down wages. In normal times, wages fall so some of these workers reallocate to the traded goods sector. At the same time, some others 'return' to work in the nontraded sector. When the constraint is binding, however, these second-round effects cannot happen: the fall in the price of nontradables results in an increase in unemployment and in a larger fall in the production of nontraded goods.

Figure 7 makes this point by showing that the supply curve is flatter when the constraint on wages is binding. This means that when demand falls, quantities fall more and prices fall less than in normal times. Wage rigidities create price stickiness.

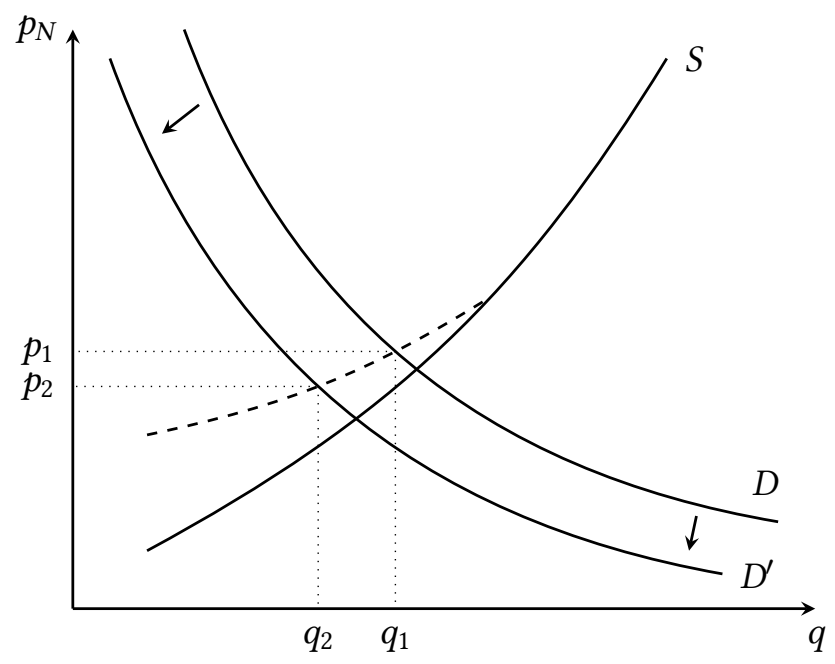

Figure 7: Market Clearing in the Nontradable Sector

The introduction of wage rigidities in this paper departs from the traditional approach of SchmittGrohé and Uribe (2016). In it, the wage in period $t$ is constrained be no less than $\gamma_{w} w_{t-1}$, where $\gamma_{w} \leq 1$ is a parameter. I follow instead Bianchi, Ottonello, and Presno (2016) and set a constant lower bound $\bar{w}$ 
on nominal wages. While both assumptions are similar, in this context there are some advantages to the second formulation.

The first obvious advantage is that not having to carry the previous period wage saves one state variable. But there is a second advantage: in the traditional formulation good TFP shocks can be welfare-decreasing if they push the current wage rate too high and generate future unemployment. This is the 'overborrowing' externality emphasized by Schmitt-Grohé and Uribe (2016): individual households do not internalize that their consumption pushes up wages. In a scenario like this, where defaults also artificially depress TFP, a benevolent government might want to default on its debt only to suppress the overconsumption externality. This would lead to counterfactually many defaults in good times. If the government was allowed to choose spending and debt issuances, it could use fiscal policy to curtail the boom instead of defaulting. However, I am constraining the government to follow the estimated fiscal rules. Hence, the admittedly less realistic constant lower bound on wages is preferred.

\section{CAlibration}

\subsection{Fiscal rules}

I estimate fiscal rules for government spending and issuances of new debt, using quarterly data for Spain. Data are taken from Eurostat and cover the period 1999Q1 to 2017Q4. In the model, government consumption and net issuances as fractions of GDP depend on the whole state vector, so in the data I regress those against endogenous variables.

Table 2 summarizes the results. For each dependent variable, the first column contains the preferred specification. The second one reports a simpler version of the same regression. The fit for both government consumption and debt issuances is good, with adjusted $R^{2} \mathrm{~s}$ at $90 \%$ and $70 \%$, respectively. Fiscal policy is countercyclical, with positive responses to unemployment for both spending and issuances. New issuances respond negatively to the debt-to-GDP ratio, consistent with debt stabilization. Figure 8 shows the fitted values for Spain from the preferred specification. The predicted rules track the observed series closely.

\subsection{Model parameters}

The current calibration of the model is able to generate a good match to some critical standard targets in the literature. Table 3 reports some critical parameter values. Because of the numerical complexity of the model, I rely on external calibration as much as possible. For the supply side of the economy, I closely follow Anzoategui (2020) and Stockman and Tesar (1995) and set preference parameters $₫$ and $\vartheta_{N}$ to match the shares of traded and nontraded goods in both private and public consumption, as well as the elasticity

$\eta$ to the elasticity of relative consumption demand. Because of CES demand, every household consumes 


\begin{tabular}{|c|c|c|c|c|}
\hline & \multicolumn{2}{|c|}{$G_{t} / Y_{t}$} & \multicolumn{2}{|c|}{$\left(B_{t}^{\prime}-(1-\rho) B_{t}\right) / Y_{t}$} \\
\hline & (1) & $(2)$ & (3) & (4) \\
\hline Constant & $\begin{array}{c}13.194^{* * *} \\
(1.350)\end{array}$ & $\begin{array}{c}14.352^{* * *} \\
(0.982)\end{array}$ & $\begin{array}{c}2.680 \\
(3.087)\end{array}$ & $\begin{array}{c}1.027 \\
(1.407)\end{array}$ \\
\hline Unemployment $_{t}$ & $\begin{array}{l}1.078^{* * *} \\
(0.086)\end{array}$ & $\begin{array}{l}0.330^{* * *} \\
(0.028)\end{array}$ & $\begin{array}{l}0.410^{*} \\
(0.197)\end{array}$ & $\begin{array}{c}0.286^{* * *} \\
(0.042)\end{array}$ \\
\hline Unemployment $_{t}^{2}$ & $\begin{array}{c}-0.020^{* * *} \\
(0.002)\end{array}$ & & $\begin{array}{r}-0.003 \\
(0.005)\end{array}$ & \\
\hline$B_{t} / Y_{t}$ & $\begin{array}{c}-0.187^{* * *} \\
(0.028)\end{array}$ & $\begin{array}{l}-0.021^{*} \\
(0.010)\end{array}$ & $\begin{array}{l}-0.099 \\
(0.063)\end{array}$ & $\begin{array}{l}-0.020 \\
(0.015)\end{array}$ \\
\hline$\left(B_{t} / Y_{t}\right)^{2}$ & $\begin{array}{l}0.001^{* * *} \\
(0.000)\end{array}$ & & $\begin{array}{c}0.001 \\
(0.000)\end{array}$ & \\
\hline Net Exports ${ }_{t}$ & $\begin{array}{c}-0.309^{* * *} \\
(0.070)\end{array}$ & $\begin{array}{l}-0.167 \\
(0.096)\end{array}$ & $\begin{array}{c}0.233 \\
(0.162)\end{array}$ & $\begin{array}{c}0.212 \\
(0.138)\end{array}$ \\
\hline Observations & 72 & 72 & 71 & 71 \\
\hline$R^{2}$ & 0.916 & 0.776 & 0.814 & 0.808 \\
\hline
\end{tabular}

Standard errors in parentheses. ${ }^{\star \star \star} p<0.01,{ }^{\star \star} p<0.05,{ }^{\star} p<0.1$.

Table 2: Estimated Fiscal Rules

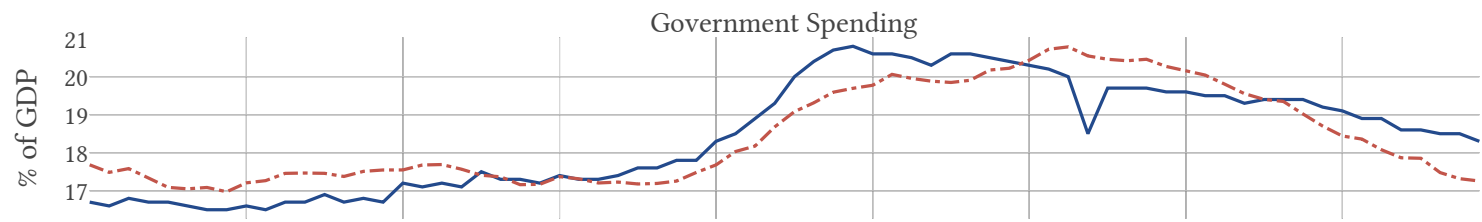

Debt Issuances

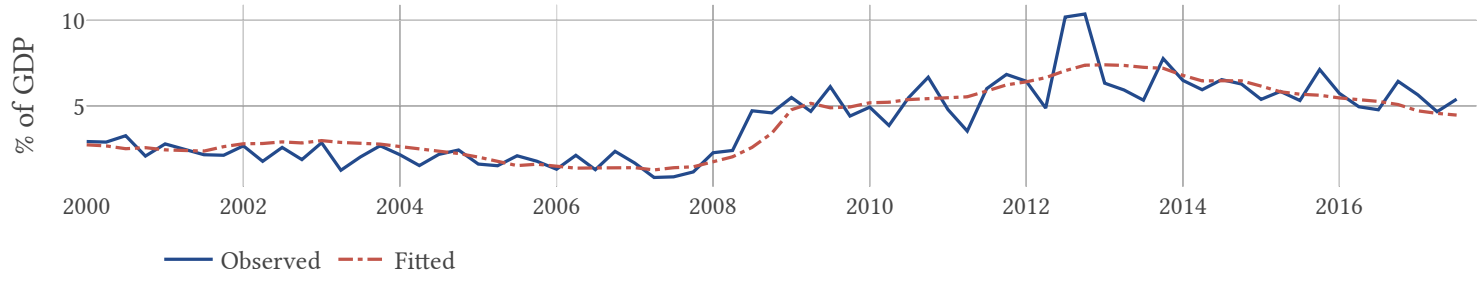

Figure 8: Estimated Fiscal Rules 
traded and nontraded goods in the same proportions. Therefore, $₫$ and $\eta$ only link prices and aggregate quantities through

$$
p_{N t}=\frac{\omega^{1 / \eta}}{1-\omega^{1 / \eta}}\left(\frac{C_{T t}}{C_{N t}}\right)^{\frac{1}{\eta}}
$$

so the estimation from Stockman and Tesar (1995) is valid in this context as well.

\begin{tabular}{|c|c|c|c|}
\hline Description & Parameter & Value & Source / Target \\
\hline \multicolumn{4}{|c|}{ Debts and defaults } \\
\hline Risk-free rate & $r^{\star}$ & $4 \%$ ann. & Anzoategui (2020) \\
\hline Haircut in case of default & $\hbar$ & $45 \%$ & Philippon and Roldán (2018) \\
\hline TFP loss in case of default & $\Delta$ & $10 \%$ & Philippon and Roldán (2018) \\
\hline Reentry probability & $\theta$ & 0.04167 & Cruces and Trebesch (2013) \\
\hline \multicolumn{4}{|c|}{ Traded and nontraded goods } \\
\hline Share of nontraded in prod & $\varpi$ & 0.7397 & Anzoategui (2020) \\
\hline Labor share in prod & $\alpha_{N}, \alpha_{T}$ & 0.67 & Anzoategui (2020) \\
\hline Share of nontraded in $G$ & $\vartheta_{N}$ & $88 \%$ & Anzoategui (2020) \\
\hline Elasticity of nontraded consumption & $\eta$ & 0.74 & Anzoategui (2020) \\
\hline \multicolumn{4}{|c|}{ Idiosyncratic income and preferences } \\
\hline Persistence $\log \varepsilon_{i t}$ & $\rho_{\varepsilon}$ & 0.978 & D’Erasmo and Mendoza (2016) \\
\hline Std. deviation $\log \varepsilon_{i t}$ & $\sigma_{\varepsilon}$ & 0.022 & D’Erasmo and Mendoza (2016) \\
\hline Elasticity of intertemporal substitution & $\psi$ & 1 & Epstein - Zin $=$ robustness \\
\hline \multicolumn{4}{|c|}{ Internally calibrated } \\
\hline Discount rate of $\mathrm{HHs}$ & $1 / \beta-1$ & $5.615 \%$ ann. & Moments in Table 4 \\
\hline Risk aversion & $\gamma$ & 3 & Moments in Table 4 \\
\hline Progressivity of tax schedule & $\tau$ & $28 \%$ & Moments in Table 4 \\
\hline Wage minimum & $\bar{w}$ & 1.175 & Moments in Table 4 \\
\hline TFP process & $\rho_{z}, \sigma_{z}$ & $(0.63,0.011)$ & Moments in Table 4 \\
\hline Mean risk premium & $\bar{\xi}$ & $0.05 \%$ & Moments in Table 4 \\
\hline Risk premium AR(1) & $\rho_{\xi}, \sigma_{\xi}$ & $(0.95,0.00025)$ & Moments in Table 4 \\
\hline Mean utility cost of default & $\mu_{g}$ & 0.012 & Moments in Table 4 \\
\hline
\end{tabular}

Table 3: Parameter Values

The risk-free interest rate is set at a standard value in the literature. For the costs of default, I follow Philippon and Roldán (2018) and set the haircut and conditional TFP losses to a Greek-style default. The probability of reentry is set to give an expected duration of default of 25 quarters, on the lower end of the Cruces and Trebesch (2013) estimation for large haircuts. 
As for the household idiosyncratic income shocks process, I follow the estimation of D'Erasmo and Mendoza (2016) based on the Spanish income distribution for the same period that I study.

Table 4 provides details on the fit of the model. Statistics in the Model column are computed by averaging 40 simulations of 700 years each. The fit of the model is generally good. The Spanish sample has one crisis for 17 years of data, which is plausibly higher than the ergodic frequency. For this reason, in the calibration I informally target lower levels of unemployment and debt-to-GDP. At the time of this writing, the Gini coefficient on wealth falls short of its value in the data. However, the gap is smaller during crisis (see Figure 14).

\begin{tabular}{lcc}
\hline Target & Model & Data \\
\hline AR(1) autocorr. coef $\log \left(Y_{t}\right)$ & 0.937 & 0.966 \\
AR(1) std coef $\log \left(Y_{t}\right)$ & $0.658 \%$ & $0.617 \%$ \\
AR(1) autocorr. $\operatorname{coef} \log \left(C_{t}\right)$ & 0.964 & 0.954 \\
AR(1) std coef $\log \left(C_{t}\right)$ & $0.789 \%$ & $1.22 \%$ \\
Avg spread (bps) & 122 & 106 \\
AR(1) autocorr. coef spread & 0.98 & 0.967 \\
AR(1) std coef spread & 23.5 & 30.1 \\
Avg Debt-to-GDP & $46.3 \%$ & $64.6 \%$ \\
Std Debt-to-GDP & $6.73 \%$ & $23.5 \%$ \\
Avg unemployment & $10.3 \%$ & $15.9 \%$ \\
Std unemployment & $2.23 \%$ & $6.09 \%$ \\
Median dom holdings & $63.8 \%$ & $56.5 \%$ \\
Avg wealth-to-GDP & $94 \%$ & $94.5 \%$ \\
Avg wealth Gini & $48.5 \%$ & $57.5 \%$ \\
\hline
\end{tabular}

TABle 4: Model Fit

All data from Eurostat 2000Q1:2017Q4, except Gini index from Eurostat 2010, private consumption from OECD 2000Q1:2017Q4, domestic holdings from Banco de España, 2004Q1:2017Q4

\subsection{Accuracy of the simulation}

To evaluate the accuracy of the approximation to the actual distribution of households across their idiosyncratic states, in each simulation I conduct the following tests. In period $t$, given the aggregate state variables in $\mathrm{S}_{t}=\left(B_{t}, \mu_{t}, \sigma_{t}, \xi_{t}, \zeta_{t}, z_{t}\right)$, I compute the 'theoretical' value of some endogenous variables $x_{t}$ from the model solution at this state. I then compare it with the 'actual' value which results from market clearing taking into account the actual distribution $\lambda_{t}$. Table 5 reports the average of the absolute value of the relative discrepancies and shows that assuming a lognormal distribution does not result in large errors. 


\begin{tabular}{lc}
\hline Variable & Avg. relative discrepancy \\
\hline Price of nontraded goods & $0.14 \%$ \\
Consumption & $0.59 \%$ \\
\hline
\end{tabular}

TABle 5: Discrepancies in Simulation

\section{Analysis}

\subsection{Government policy}

Figure 9 shows the government's value function $\mathcal{W}\left(\Psi\left(\mathrm{S}, \zeta^{\prime}, z^{\prime}, \zeta^{\prime}\right), h^{\prime}\right)$ of the following period as function of the realization of shocks. Each panel shows welfare as a function of next period's TFP realization $z^{\prime}$. The first row corresponds to a low realization of $\xi^{\prime}$, while in the second row the risk premium is high. Finally, the columns consider different $\mathrm{S}$ for the current period: initial debt increases from left to right. Higher debt levels increase the value of default relative to repayment. For intermediate amounts of initial debt, moreover, a higher realization of future TFP raises the relative value of repayment. Higher spreads also marginally raise the relative value of default.

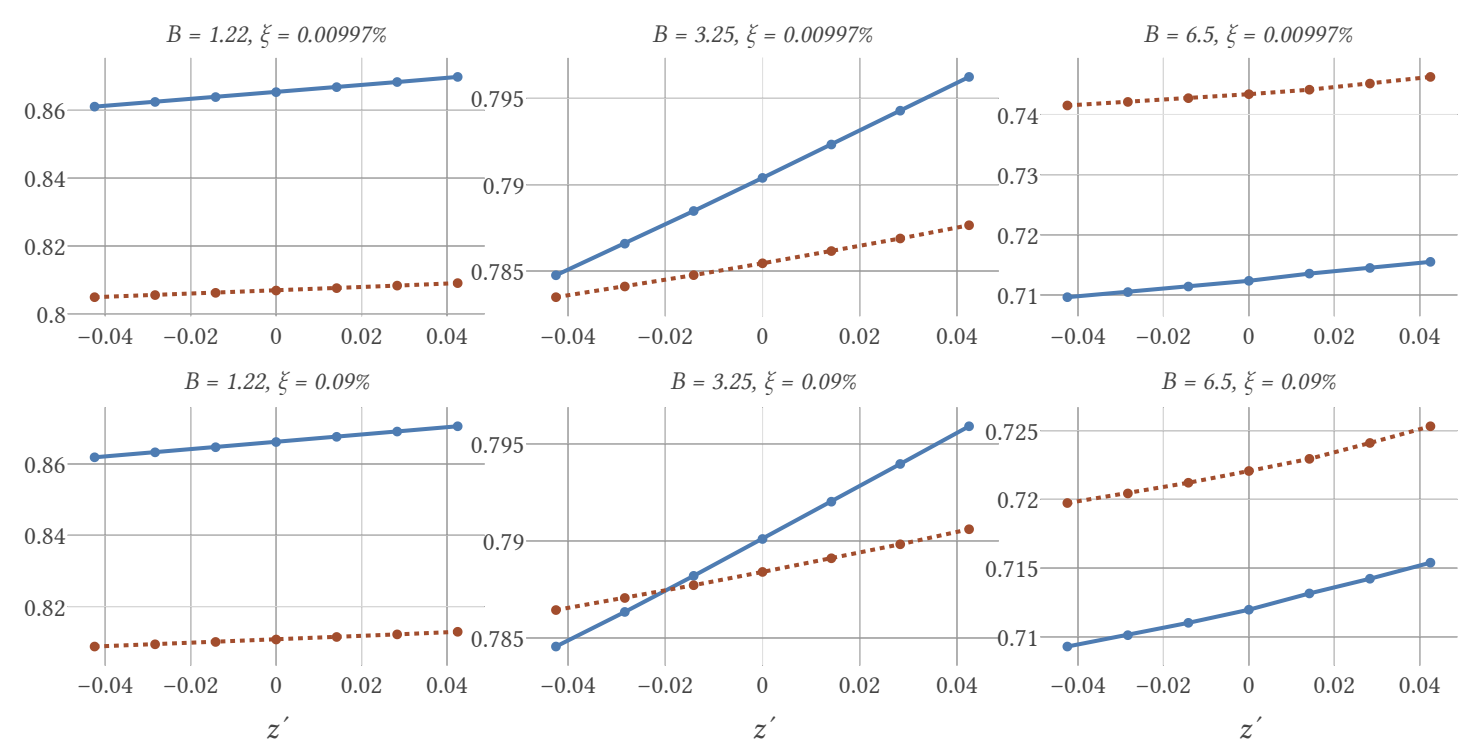

Figure 9: Welfare Functions

Note: Blue lines plot the value of repayment, red dashed lines plot the value of default

Figure 10 shows the lump-sum transfers that would clear the government's budget constraint in states $\Psi\left(\mathrm{S}, \xi^{\prime}, z^{\prime}, \zeta^{\prime}\right)$ of next period, as a function of $\left(\xi^{\prime}, z^{\prime}, \zeta^{\prime}\right)$. Unsurprisingly, high levels of indebtedness shrink the government budget constraint and force it to collect high lump-sum taxes. In repayment, a higher level of future TFP induces high lump-sum taxes as well. This effect is driven by relatively low unemployment 
in those states, which leaves room for the government to reduce its leverage.

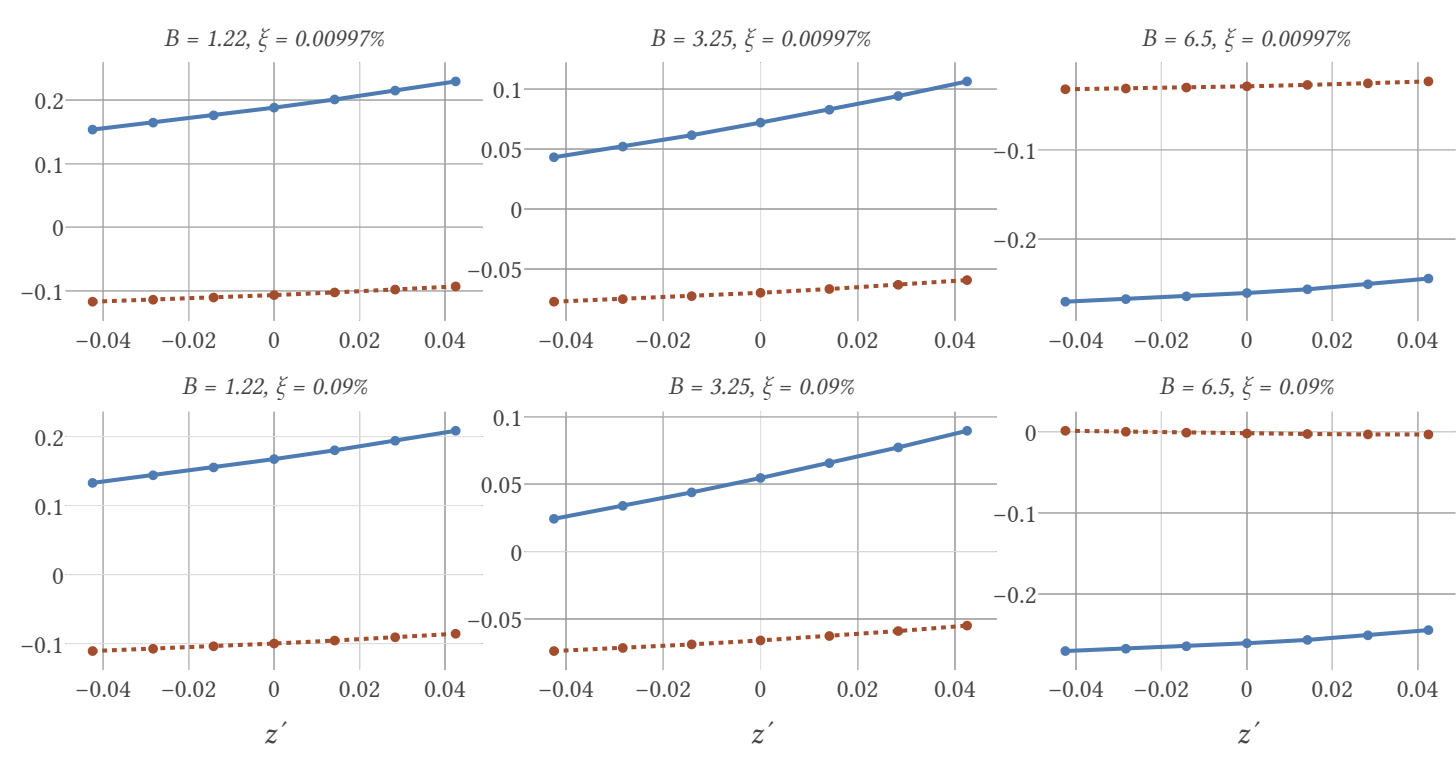

Figure 10: Transfers

Note: Blue lines plot transfers in repayment, red dashed lines plot transfers in default

Figure 11 shows the price of debt $q^{g}(\mathrm{~S})$ at different states $\mathrm{S}$. The left panel shows that spreads rise (the price of debt falls) steeply when debt reaches a certain threshold. The effect of TFP is less stark but higher values of $z$ are associated with lower spreads. Both of these are taken for a fixed distribution when the economy is not in default.

The right panel shows the impact of the distribution (for fixed values of $B$ and $z$ when the economy is not in default). Higher spreads occur when the economy is poorer and more unequal. This is because the value of autarky depends strongly on how rich the economy is: with lower aggregate wealth, more agents are close to their borrowing limit and would suffer from the loss in TFP (and hence wages and employment) that follows a default. The effect of variance also goes through the value of autarky but through a different channel: when inequality is greater, defaults become a better way to redistribute.

\subsection{Macroeconomic conditions}

The unemployment rate is shown in Figure 12. Unemployment decreases with productivity and increases with government debt. The right panel shows that unemployment is related negatively to total wealth and positively to inequality. 

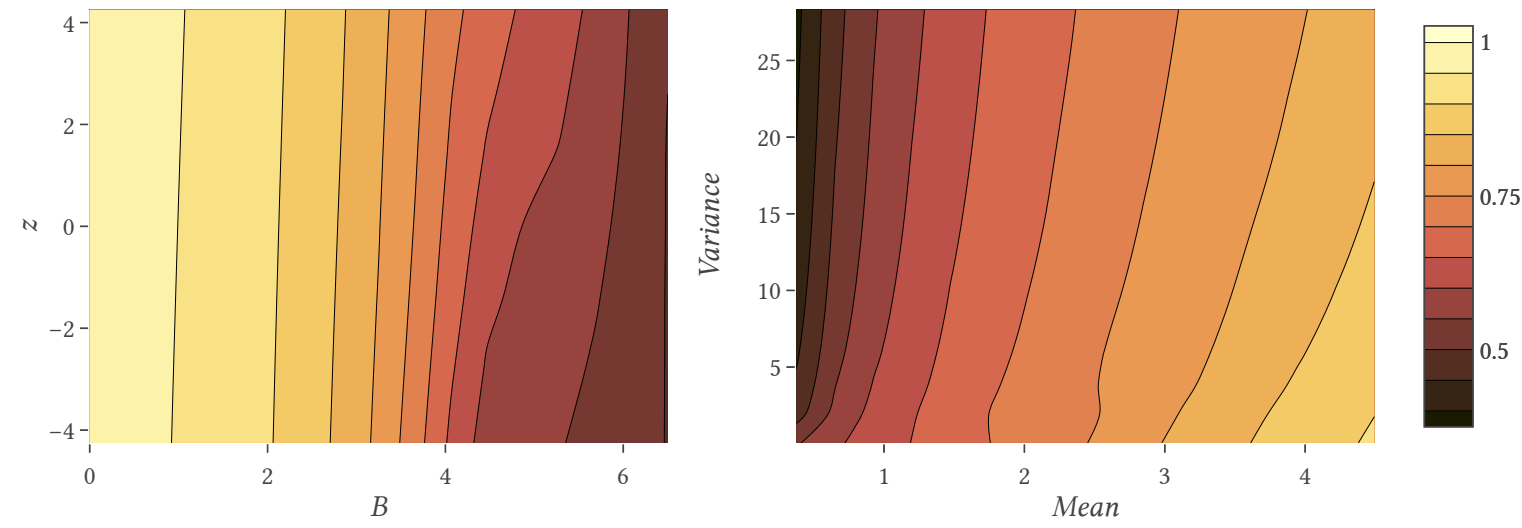

Figure 11: Price of Debt
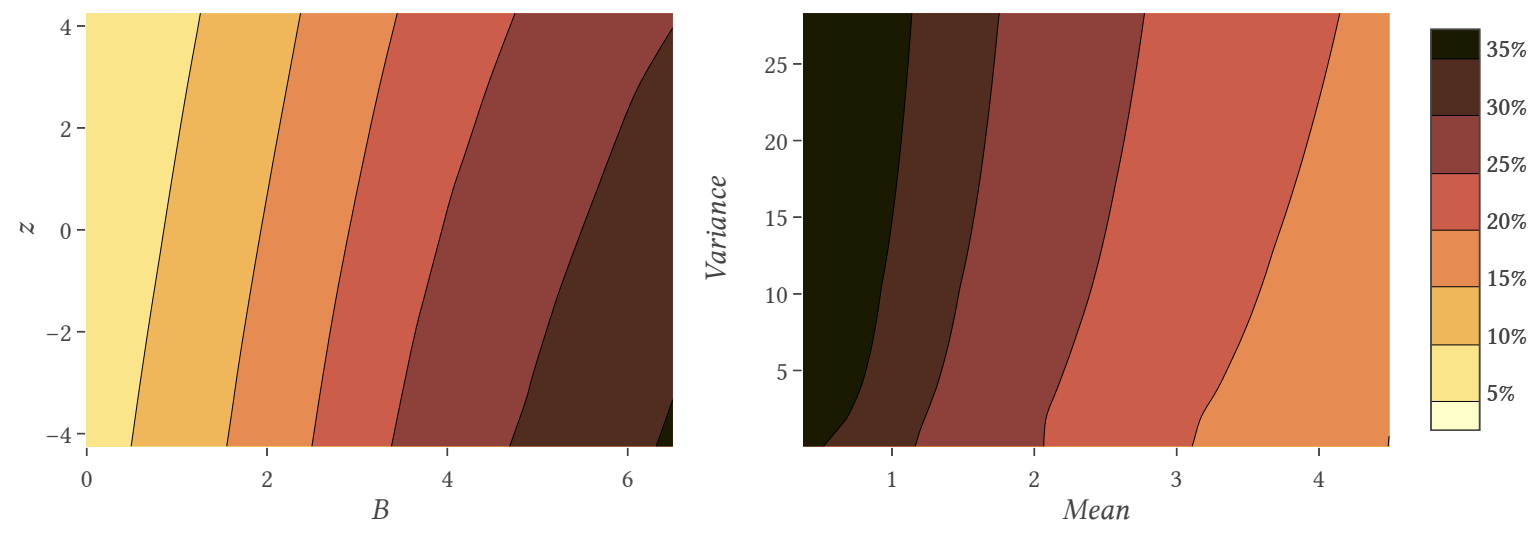

Figure 12: Unemployment 


\subsection{Ergodic distributions}

Figure 13 plots estimated densities for output and consumption along the simulated path. To compute these, I subtract the mean and divide by the standard deviation of each variable. The estimated densities reveal a left skew in consumption.

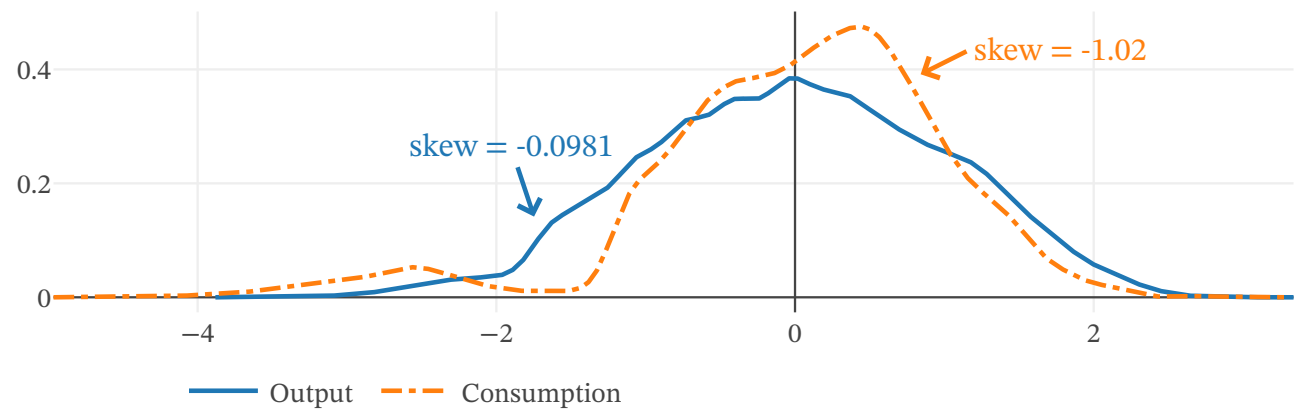

Figure 13: Ergodic Densities for Normalized Output and Consumption

Figure 18 in the Appendix recomputes the density of normalized output and consumption conditioning on a positive default probability (but still normalizing as before). This exercise reveals that the extra mass on the left tail of consumption comes from crisis episodes. Figure 19 shows the fears of savers: conditional on default, output and (especially) consumption fall to extremely negative levels. Most of the mass of the consumption distribution is between 2 and 4 standard deviations below the unconditional mean.

\section{CRISES}

Using the simulated series, I focus on episodes of crisis. I define an episode of high spreads as a period of 11 quarters (to match the Spanish experience of 2010-mid 2012) at the end of which the spread surpasses 4 oobps but a default does not happen. I further condition on lower spreads at the start of the episode. Even though it matches the spread volatility, the model does not seem to generate such sharp accelerations of the spread as the crisis of 2010. I condition on lower spreads at the start of the episode subject to keeping a reasonable number of episodes in the sample.

Figure 14 plots endogenous variables around episodes of high spreads, projecting about a year into the past for context. Time is shown in years (this means that the crisis episode starts around -1.5 in the charts).

TFP, output, and consumption are significantly below their normal-times values. The government's finances deteriorate and lump-sum taxes increase. Furthermore, as unemployment increases tax collections worsen. A high propensity to save pushes up the mean of the wealth distribution while the Gini coefficient 

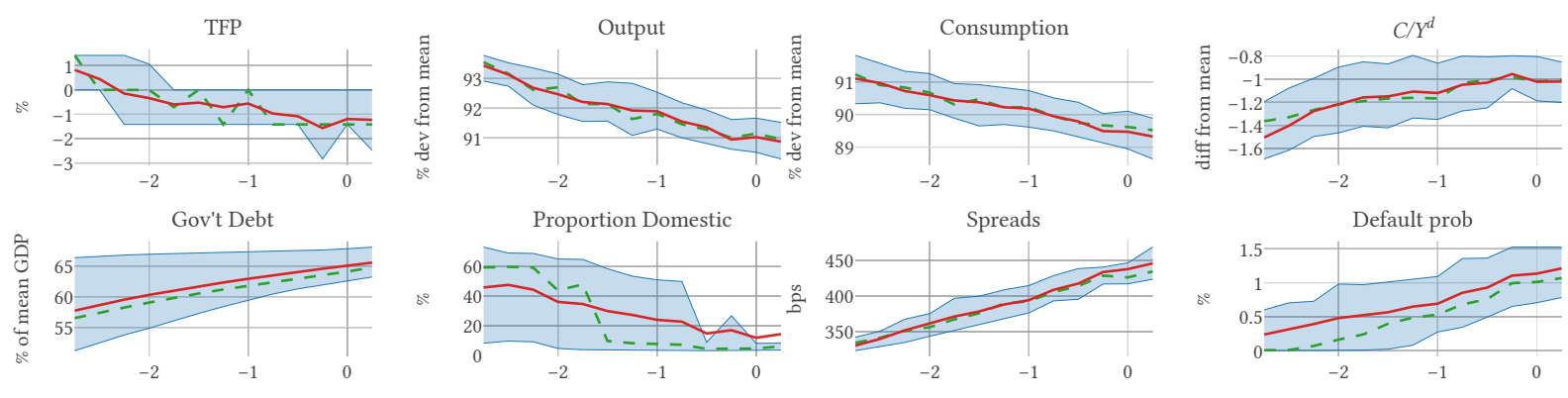

Proportion Domestic
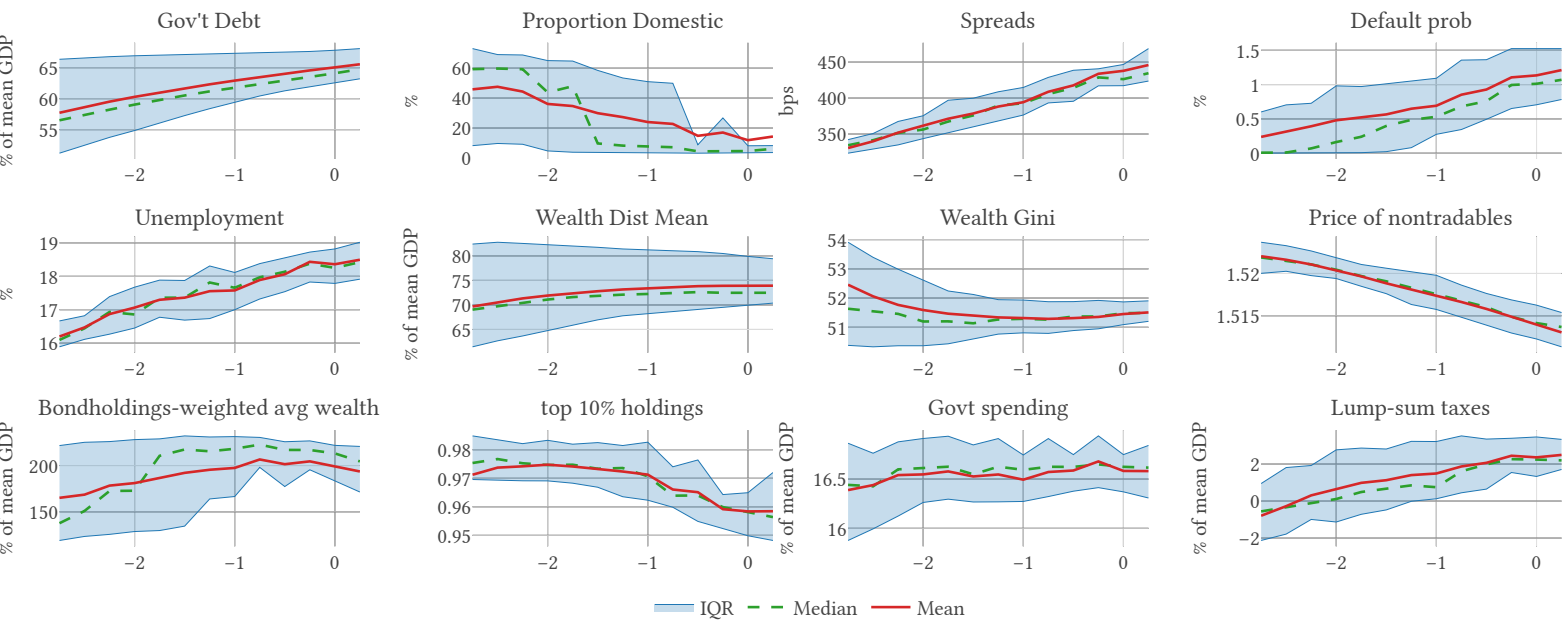

Figure 14: Times of High Spreads

falls by about a point right before the crisis but picks up marginally during it (this is counterfactual as inequality went up in Spain between 2010 and 2014). Output hits a minimum of about $9 \%$ below its longrun mean, while TFP varies between $0 \%$ and $-2 \%$ at the trough of the episode. Consumption also drops significantly below its long-run mean by about $11 \%$. These numbers for the recession match exactly the peak-to-trough contractions in the data. The average propensity to save is also elevated during the crisis: the typical household consumes about 1pp. of disposable income less than in normal times.

Figure 14 shows some of the dynamics at play. In the buildup to the crisis consumption falls both in levels and as a fraction of a measure of disposable income. There is also a significant fiscal contraction: there is a sustained increase in taxes along with a slight fall in government spending. Government spending is the result of two forces: in the fiscal rule, the government spends more when unemployment increases but also has the stabilize the level of debt. The level of government accumulates rapidly during the crisis as a consequence of high spreads.

Figure 15 shows the behavior of the economy around defaults, for comparison.

Most variables exhibit a jump at the moment of default: output falls driven both directly and indirectly (through unemployment) by effective TFP, the level of debt reflects the haircut applied at default, etc. Default itself creates a large destruction of private wealth accompanied by a substantial increase in inequality. Both factors contribute to a jump in the aggregate propensity to save. 

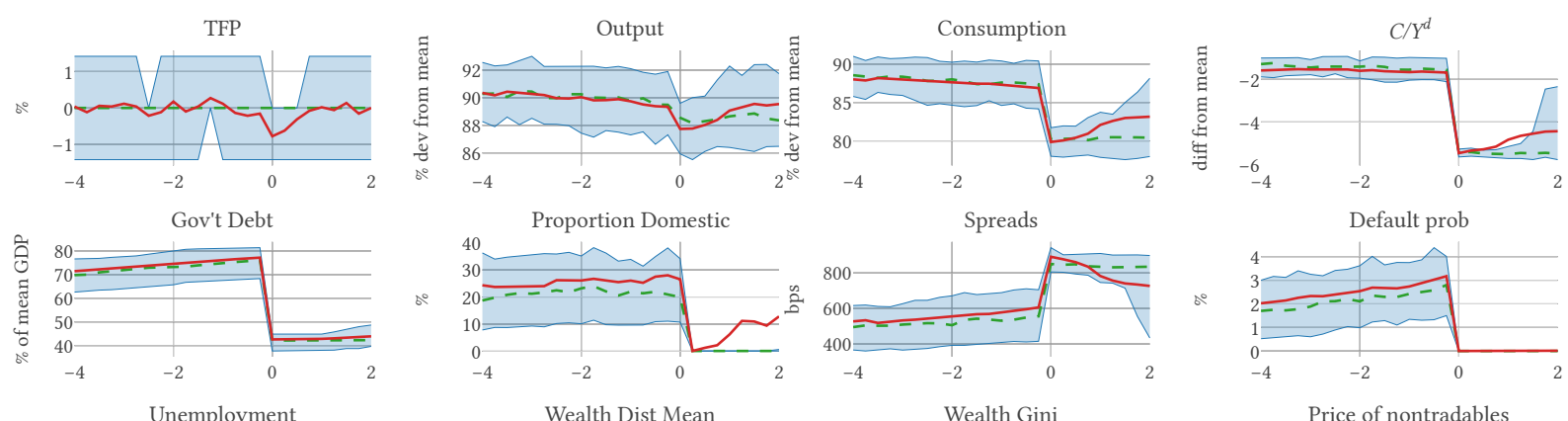

Proportion Domestic

Spreads
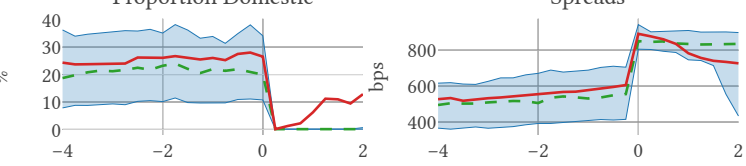

Wealth Dist Mean

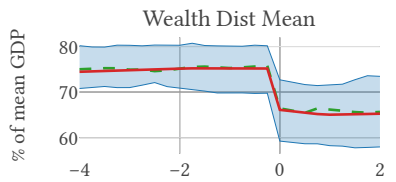

Wealth Gini
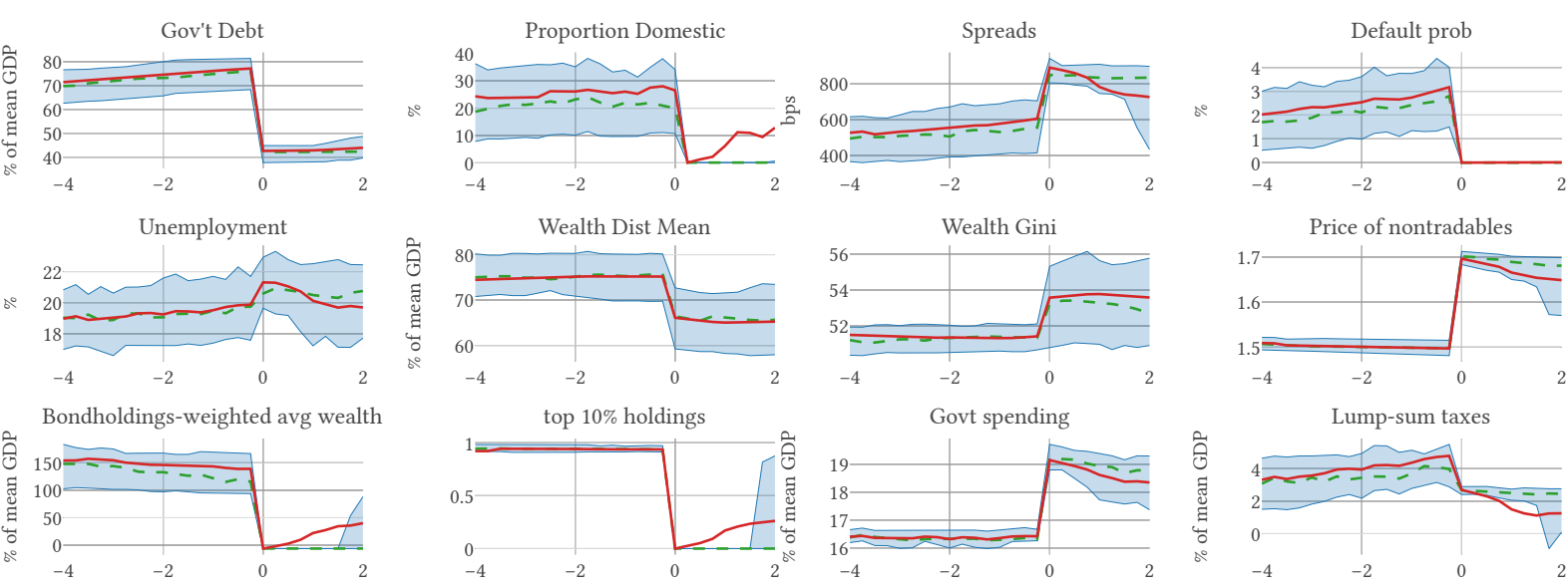

IQR - - Median — Mean

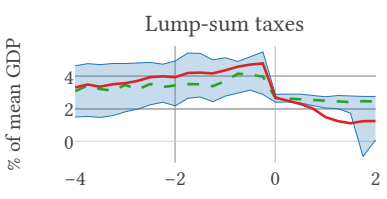

Figure 15: Outcomes ARound Defaults

\subsection{Amplification forces}

I now consider the benchmark economy and its episodes of high spreads and compare it with an alternate economy in which the government follows a policy of always repaying the debt.

Figure 16 presents a comparison between the times in which the benchmark economy is in crisis and the same time periods of a simulation of the no-default economy (with the same shocks). I show output, consumption, and government debt as percent deviations from their initial levels. The contractions in output and consumption are muted in the no-default economy. Because the no-default economy has a higher average propensity to consume (shown in levels), aggregate demand is at its normal level, meaning that output and consumption only fall because of the underlying shock to TFP. Moreover, in the benchmark economy the dynamics (as well as the higher level) of spreads induce an acceleration of the debt-to-GDP ratio. All in all, the no-default economy suffers an output and consumption contraction of between $50 \%$ and $60 \%$ smaller than the benchmark.

Fiscal policy also differs across both models. The benchmark economy is forced to a larger increase in lump-sum transfers, while the no-default economy can keep a fiscal policy stance closer to neutral.

The differences in welfare are substantial. The specification of preferences is such that the value function equals the level of permanent consumption (a constant amount which would yield the same utility). At the height of a crisis, the average household would give up the equivalent of as much as $12 \%$ of consumption to be able to move to the economy with no default. 
Comparing the benchmark economy with the version where default is not possible, crisis events are associated sharper contractions in output and especially in consumption. These events are also associated with an acceleration of debt as the price of debt deteriorates. Unemployment also diverges during crises, as the government is forced to implement what looks like a fiscal adjustment, by increasing lump-sum taxes and cutting on government spending.

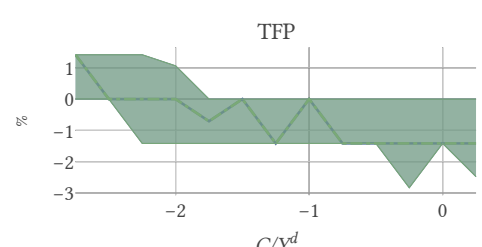

$C / Y^{d}$
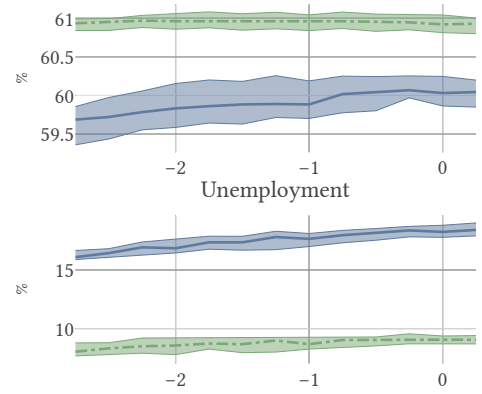

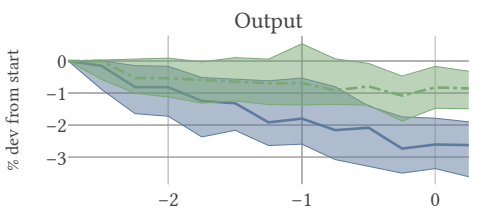

Gov't Debt

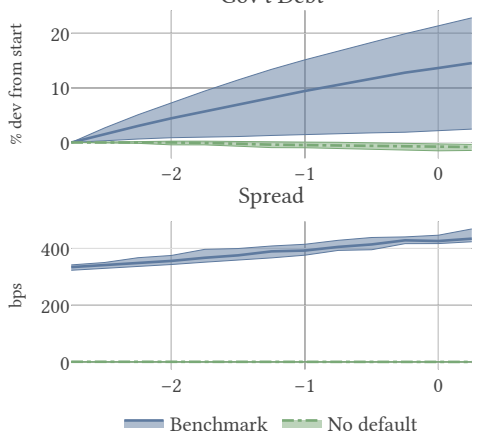

FIGURE 16: CRISES

Note: Interquartile ranges shaded

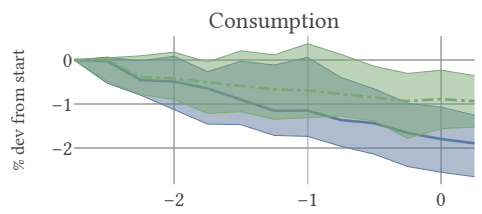

Lump-sum taxes

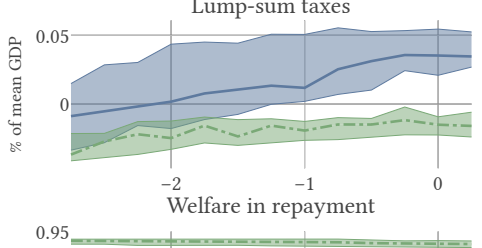

0.95

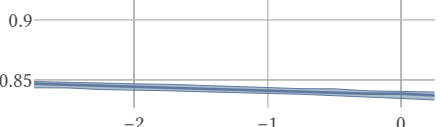

Table 6 shows statistics from simulation of the both models. It illustrates how sovereign risk affects the economy even in normal times. The volatilities of output and consumption are $20 \%$ and $25 \%$ lower without the possibility of default. Spreads are obviously absent from the no-default simulation (they are only positive because of the $\xi$ shock to risk premia). Unemployment and government debt are both lower in the economy without default. Because the economy is less risky overall, the scope for precautionary savings is lower, which results in a lower private wealth-to-GDP ratio and an increase in the Gini coefficient as wealth becomes more correlated with current income. As a result of all these differences, the average household would be willing to give up $4.2 \%$ of permanent consumption to make defaults impossible.

\subsection{The distributional impact of sovereign risk}

Figure 17 plots the welfare costs of sovereign risk across the wealth distribution during the same episodes of crises studied earlier. The gains from removing the possibility of default are heterogeneous, decreasing in wealth, and range from $13.2 \%(12.5 \%)$ for the bottom $10 \%(25 \%)$ of the distribution to $10.6 \%$ (11.8\%) for the top $10 \%(25 \%)$. The median household would pay $12.2 \%$ of permanent consumption to abolish default, compared to about $12.3 \%$ for the average, which enters the government's objective function. 


\begin{tabular}{lcc}
\hline Moment & Benchmark & No default \\
\hline AR(1) autocorr. $\operatorname{coef} \log \left(Y_{t}\right)$ & 0.937 & 0.815 \\
AR(1) std coef $\log \left(Y_{t}\right)$ & $0.658 \%$ & $0.523 \%$ \\
AR(1) autocorr. $\operatorname{coef} \log \left(C_{t}\right)$ & 0.964 & 0.898 \\
AR(1) std coef $\log \left(C_{t}\right)$ & $0.789 \%$ & $0.471 \%$ \\
Avg spread (bps) & 122 & 1.2 \\
AR(1) autocorr. coef spread & 0.98 & 0.874 \\
AR(1) std coef spread & 23.5 & 0.134 \\
Avg Debt-to-GDP & $46.3 \%$ & $36.6 \%$ \\
Std Debt-to-GDP & $6.73 \%$ & $1.83 \%$ \\
Avg unemployment & $10.3 \%$ & $8.12 \%$ \\
Std unemployment & $2.23 \%$ & $0.84 \%$ \\
Median dom holdings & $63.8 \%$ & $246 \%$ \\
Avg wealth-to-GDP & $94 \%$ & $83 \%$ \\
Avg wealth Gini & $48.5 \%$ & $50.9 \%$ \\
Default frequency & $0.243 \%$ & $0 \%$ \\
Welfare in repayment & 0.906 & 0.944 \\
\hline
\end{tabular}

TABle 6: Models
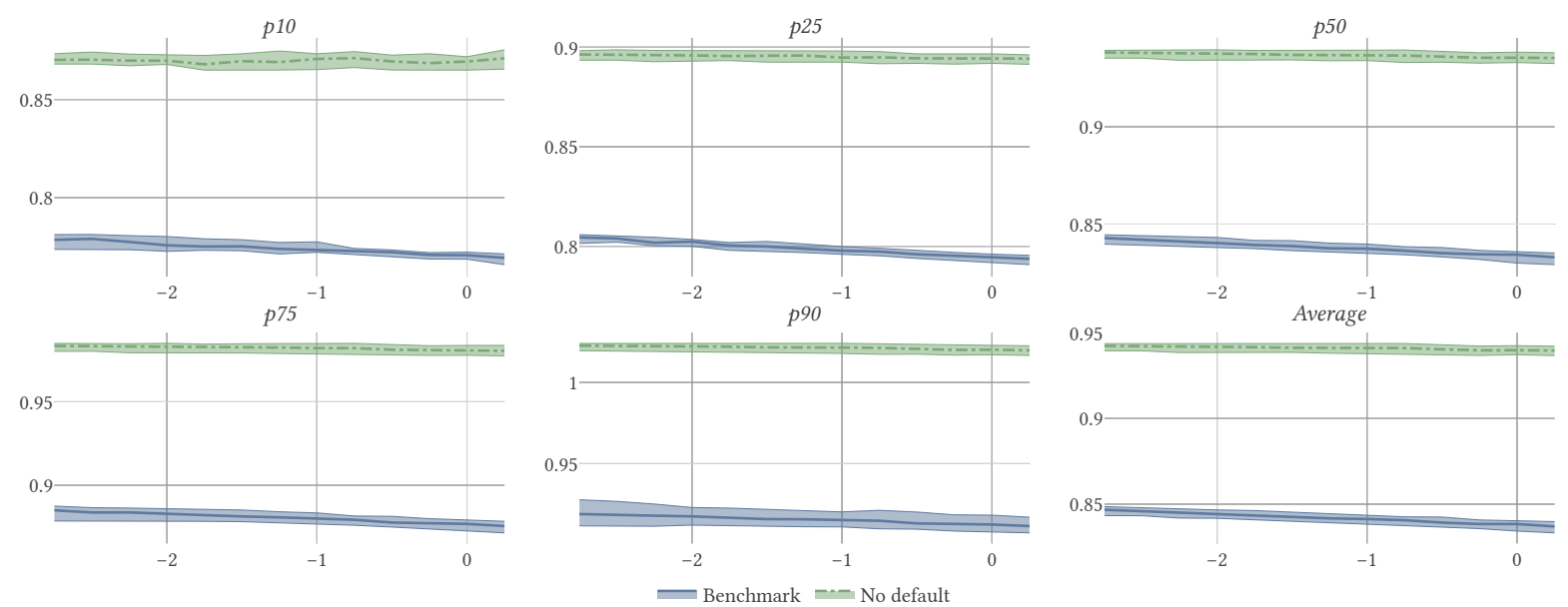

Figure 17: VAlue FUnCTIONS IN CRISES

Note: Interquartile ranges shaded 
Finally, Table 7 summarizes the welfare gains of eliminating sovereign risk for different quantiles of the distribution, averaging over all time periods. The first two columns report the average of the welfare function for each percentile of the wealth distribution in the benchmark and no-default models, while the last column shows the welfare gains of moving from the benchmark to the no-default models keeping constant the position in the wealth distribution. Welfare gains also decline with wealth and range between $3.68 \%$ to just above $5 \%$ of permanent consumption.

\begin{tabular}{lccc}
\hline Moment & Benchmark & No default & Gains \\
\hline$p 10$ & 0.831 & 0.873 & $5.04 \%$ \\
$p 25$ & 0.859 & 0.898 & $4.55 \%$ \\
$p 50$ & 0.902 & 0.94 & $4.18 \%$ \\
$p 75$ & 0.948 & 0.985 & $3.92 \%$ \\
$p 90$ & 0.988 & 1.02 & $3.68 \%$ \\
Average & 0.906 & 0.944 & $4.19 \%$ \\
\hline
\end{tabular}

TABLE 7: THE WELFARE COSTS OF SOVEREIGN RISK

\section{Concluding Remarks}

Inspired by events in the Eurozone crisis, this paper analyzes a model in which households' consumption demand is negatively affected by the presence of sovereign risk. The mechanisms in the model generate substantial amplification of underlying shocks even if the risk of default does not materialize.

The amplification mechanism relies on the precautionary motives of households, which are magnified by sovereign risk. Sovereign risk creates endogenous shifts in demand conditions which exacerbate the equilibrium volatility of aggregate consumption. I find large welfare costs of sovereign risk, which range from about $4.2 \%$ of permanent consumption in normal times to as much as $12 \%$ at the height of a crisis.

Households increase their savings in response to sovereign risk because they anticipate income losses and redistribution in case of default. The anticipation of income losses in case of default explains most of the amplification. However, this effect interacts substantially with the anticipation of redistribution.

While I calibrate the model to Spain, the mechanism can help explain patterns in emerging-market business cycles, which also exhibit sovereign risk as a feature. Both the relative volatility of consumption to output and the volatility of output itself are typical calibration targets in the sovereign debt literature when applied to emerging-market economies. The setup presented here offers a more complete explanation of these phenomena by explicitly considering the saving behavior of private agents as well as the interest rate they face. The amplification mechanism and the welfare costs of sovereign risk are both nat- 
ural consequences of this more granular description when private agents are net savers. This is the case of Spain in the 20oos but also of salient episodes in emerging markets, when the private sector's international investment position is positive even as the government is in debt.

\section{REFERENCES}

Aguiar, M. And G. Gopinath (2006): “Defaultable Debt, Interest Rates and the Current Account,” fournal of International Economics, 69, 64-83.

--_ (2007): "Emerging Market Business Cycles: the Cycle is the Trend," Fournal of Political Economy, 115, $69-102$.

Aiyagari, S. R. AND E. R. McGrattan (1998): “The optimum quantity of debt," fournal of Monetary Economics, 42, 447-469.

Andreasen, E., G. Sandleris, And A. van der Ghote (2011): "The Political Economy of Sovereign Defaults," Business School Working Papers 2011-07, Universidad Torcuato Di Tella.

AnzoAtegui, D. (2020): "Sovereign Debt and the Effects of Fiscal Austerity," mimeo, Rutgers University.

Arellano, C. (2008): "Default Risk and Income Fluctuations in Emerging Economies," American Economic Review, 98, 690-712.

Arellano, C., Y. BAI, And L. Bocola (2017): “Sovereign Default Risk and Firm Heterogeneity,” Working Paper 23314, National Bureau of Economic Research.

Arellano, C., Y. Bai, AND G. Mihalache (2018): "Default risk, sectoral reallocation, and persistent recessions," fournal of International Economics, 112, 182-199.

Arellano, C., Y. Bai, and G. P. Mihalache (2020): "Monetary Policy and Sovereign Risk in Emerging Economies (NK-Default)," Working Paper 26671, National Bureau of Economic Research.

Arnold, I. AND S. DE VRIES-van Ewijk (2014): "The impact of sovereign and credit risk on interest rate convergence in the euro area," Dnb working papers, Netherlands Central Bank, Research Department.

Auclert, A. (2017): "Monetary Policy and the Redistribution Channel," Working Paper 23451, National Bureau of Economic Research.

BALKe, N. (2017): "The Employment Cost of Sovereign Default," mimeo, UCL.

Bianchi, J., P. Ottonello, And I. Presno (2016): "Unemployment, Sovereign Debt, and Fiscal Policy in a Currency Union,” 2016 Meeting Papers 459, Society for Economic Dynamics. 
Bloom, N. (2009): “The Impact of Uncertainty Shocks,” Econometrica, 77, 623-685.

Bocola, L. (2016): “The Pass-Through of Sovereign Risk”, fournal of Political Economy, 124, 879-926.

Chatterjee, S. And B. Eyigungor (2012): "Maturity, Indebtedness, and Default Risk," American Economic Review, 102, 2674-99.

Cruces, J. J. And C. Trebesch (2013): “Sovereign Defaults: The Price of Haircuts," American Economic fournal: Macroeconomics, 5, 85-117.

Cuadra, G., J. SÁnchez, And H. SAPriza (2010): "Fiscal Policy and Default Risk in Emerging Markets," Review of Economic Dynamics, 13, 452-469.

Deng, M. (2020): "Inequality, Taxation, and Sovereign Default Risk," Tech. rep., mimeo, Simon Fraser University.

D’Erasmo, P. And E. G. Mendoza (2016): “Optimal Domestic (and External) Sovereign Default,” Working Paper 22509, National Bureau of Economic Research.

Dovis, A., M. Golosov, And A. Shourideh (2016): "Political Economy of Sovereign Debt: A Theory of Cycles of Populism and Austerity," Working Paper 21948, National Bureau of Economic Research.

Eaton, J. And M. Gersovitz (1981): "Debt with Potential Repudiation: Theoretical and Empirical Analysis," The Review of Economic Studies, 48, 289-309.

Eggertsson, G. And P. Krugman (2012): "Debt, Deleveraging, and the Liquidity Trap: a Fisher-MinskyKoo Approach," Quarterly fournal of Economics, 1469-1513.

Ferriere, A. (2016): "Sovereign default, inequality, and progressive taxation," Working paper, European University Insitute.

Ferriere, A. AND G. NAVArro (2017): "The Heterogeneous Effects of Government Spending: It's All About Taxes,".

Gennaioli, N., A. Martin, And S. Rossi (2014): "Sovereign Default, Domestic Banks, and Financial Institutions," Fournal of Finance, 69, 819-866.

Guembel, A. And O. Sussman (2009): "Sovereign Debt without Default Penalties," The Review of Economic Studies, 76, 1297-1320.

Hansen, L. P. and T. J. Sargent (2001): "Robust Control and Model Uncertainty", American Economic Review, 91, 60-66.

Korinek, A. And A. Simsek (2016): "Liquidity Trap and Excessive Leverage," American Economic Review, 106, 699-738. 
Leland, H. E. (1998): “Agency Costs, Risk Management, and Capital Structure," fournal of Finance, 53, $1213-1243$.

Maenhout, P. J. (2004): "Robust Portfolio Rules and Asset Pricing," The Review of Financial Studies, 17, $951-983$.

Mallucci, E. (2015): "Domestic Debt and Sovereign Defaults," International Finance Discussion Papers 1153, Board of Governors of the Federal Reserve System (U.S.).

Martin, P. And T. Philippon (2017): "Inspecting the Mechanism: Leverage and the Great Recession in the Eurozone," American Economic Review, 107, 1904-37.

Martínez PAgÉs, J. (2017): “Spanish deposit-taking institutions' net interest income and low interest rates," Economic Bulletin, 1-8.

MendozA, E. G. And V. Z. Yue (2012): "A General Equilibrium Model of Sovereign Default and Business Cycles," The Quarterly fournal of Economics, 127, 889-946.

Na, S., S. Schmitt-Grohé, M. Uribe, And V. Yue (2018): “The Twin Ds: Optimal Default and Devaluation,” American Economic Review, 108, 1773-1819.

Neumeyer, P. A. ANd F. Perri (2005): "Business cycles in emerging economies: the role of interest rates," fournal of Monetary Economics, 52, 345-380.

Philippon, T. ANd F. RoldÁn (2018): “On the Optimal Speed of Sovereign Deleveraging with Precautionary Savings," IMF Economic Review, 66, 375-413.

PÉrez, D. (2018): “Sovereign Debt, Domestic Banks and the Provision of Public Liquidity, mimeo, NYU.

Romei, F. (2015): "Need for (the Right) Speed: the Timing and Composition of Public Debt Deleveraging," Economics Working Papers MWP2015/11, European University Institute.

Schmitt-Grohé, S. ANd M. Uribe (2016): "Downward Nominal Wage Rigidity, Currency Pegs, and Involuntary Unemployment," Journal of Political Economy, 124, 1466-1514.

SHIN, Y. (2006): "Ramsey Meets Bewley: Optimal Government Financing with Incomplete Markets," .

Stockman, A. C. And L. L. Tesar (1995): "Tastes and Technology in a Two-Country Model of the Business Cycle: Explaining International Comovements," The American Economic Review, 85, 168-185.

TAllarini, T. D. (2000): "Risk-sensitive real business cycles," fournal of Monetary Economics, 45, 507 - 532.

Woodford, M. (1990): "Public Debt as Private Liquidity," American Economic Review, 80, 382-388. 


\section{A. Appendix: Solution Details}

\section{A.1 The household's problem}

To make the problem more tractable, I rewrite the controls in a way that eliminates the budget constraint and replaces it with inequalities that are easier to handle. Let

$$
\begin{aligned}
s\left(a^{\prime}, b^{\prime}, \mathbf{S}\right) & =\frac{q^{h}(\mathbf{S}) a^{\prime}+q^{g}(\mathbf{S}) b^{\prime}}{q^{h}(\mathbf{S})} & \geq \bar{a} \\
\theta\left(a^{\prime}, b^{\prime}\right) & =\frac{a^{\prime}-\bar{a}}{s-\bar{a}} & \in[0,1]
\end{aligned}
$$

where the constraint set (now a rectangle) is highlighted in red and

$$
\begin{aligned}
a^{\prime}(s, \theta) & =\bar{a}+\theta_{a}(s-\bar{a}) \\
b^{\prime}(s, \theta, \mathbf{S}) & =\left(1-\theta_{a}\right)(s-\bar{a}) \frac{q^{h}(\mathbf{S})}{q^{g}(\mathbf{S})}
\end{aligned}
$$

I further decompose the household's problem into two value functions, $v$ and $w$. The first value function reflects the consumption-savings decision, while the second value function focuses on the portfolio allocation of those savings. We have

$$
\begin{gathered}
v(\omega, \varepsilon, \mathbf{S})=\max _{s, c}\left((1-\beta) c^{\frac{\psi-1}{\psi}}+\beta w(s, \varepsilon, \mathbf{S})^{\frac{\psi-1}{\psi}}\right)^{\frac{\psi}{\psi-1}} \\
\text { subject to } p_{C}\left(p_{N}\right) c+q^{h}(\mathbf{S}) s=\omega+\ell\left(\mathbf{S}, p_{N}\right) \varepsilon-T\left(\mathbf{S}, p_{N}\right) \\
s \geq \bar{a}
\end{gathered}
$$

and

$$
\begin{aligned}
& \qquad \begin{aligned}
& w(s, \varepsilon, \mathbf{S})=\max _{\theta} \mathbb{E}\left[\left(v\left(a^{\prime}+R_{b}\left(\mathbf{S}^{\prime}\right) b^{\prime}, \varepsilon^{\prime}, \mathbf{S}^{\prime}\right)\right)^{1-\gamma} \mid \omega, \varepsilon, \mathbf{S}\right]^{\frac{1}{1-\gamma}} \\
& \text { subject to } R_{b}(\mathbf{S})=1_{(\zeta=1)} \kappa+(1-\rho) q^{g}(\mathbf{S}) \\
& \theta \in[0,1] \\
& a^{\prime}=a^{\prime}(s, \theta) \\
& b^{\prime}=b^{\prime}(s, \theta, \mathbf{S})
\end{aligned}
\end{aligned}
$$

What makes this transformation so tractable is that $\omega$ and $s$ naturally belong in the same domain, so one can use the same grid for both.

\section{A.2 Solution method}

The algorithm follows closely the definition of equilibrium: to solve for an equilibrium, I solve a series of nested problems. Given government policies, I find a competitive equilibrium by finding functions of the 
aggregate state that describe the aggregates in the economy, in such a way that they are consistent with the household problem and policy functions.

Algorithm Given a policy for the government, I

1. Guess a law of motion for the distribution.

2. For each state $\mathrm{S}$

(a) Compute $q^{g}(\mathrm{~S})$ from the foreigners' sdf (10).

(b) Guess a relative price of nontradables $p_{N}$

- Get the wage rate $w$ as well as total labor demand $L^{d}$ and profits of the firms $\Pi$.

- Compute lump-sum taxes T from gov't budget constraint (with $\tau w L$ in hand).

- Solve the household's problem at prices $w, p_{N}$, profits $\Pi$, and transfers $T$.

- Check market clearing (13) for nontraded goods.

(c) Iterate on the function $p_{N}(\mathrm{~S})$ to convergence

3. Iterate on the law of motion for the distribution using the households' policy functions.

Finally, I update the government's policy according to (17) and iterate until a policy that respects it is found.

\section{A.3 More model results}

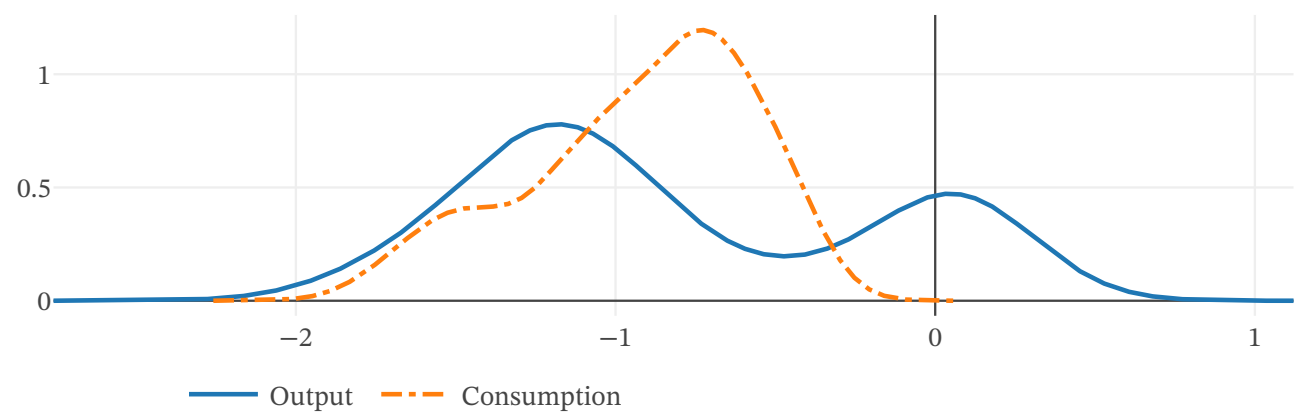

Figure 18: Densities for Output and Consumption during Crises

Densities conditional on a default probability above $15 \%$ 


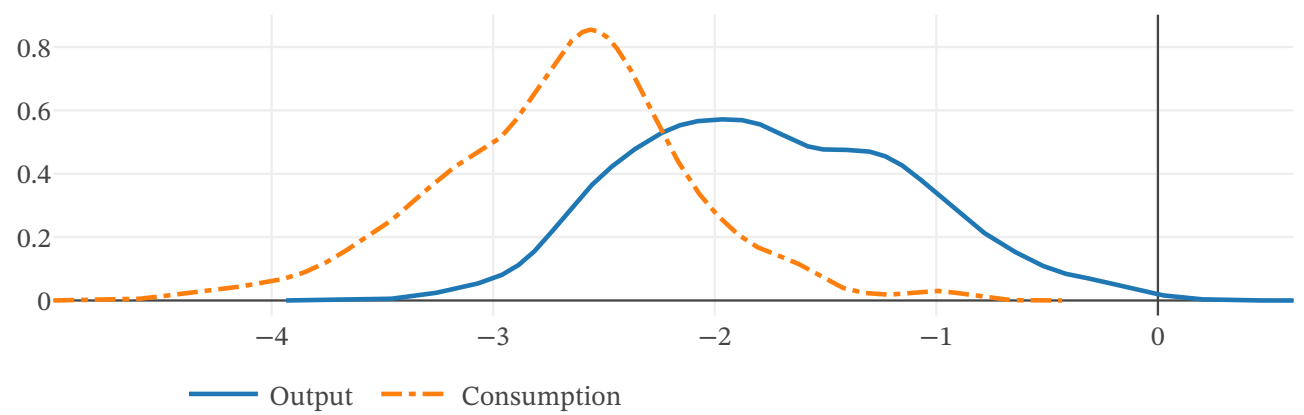

Figure 19: Ergodic Densities for Output and Consumption during Defaults

\section{B. Appendix: Evidence}

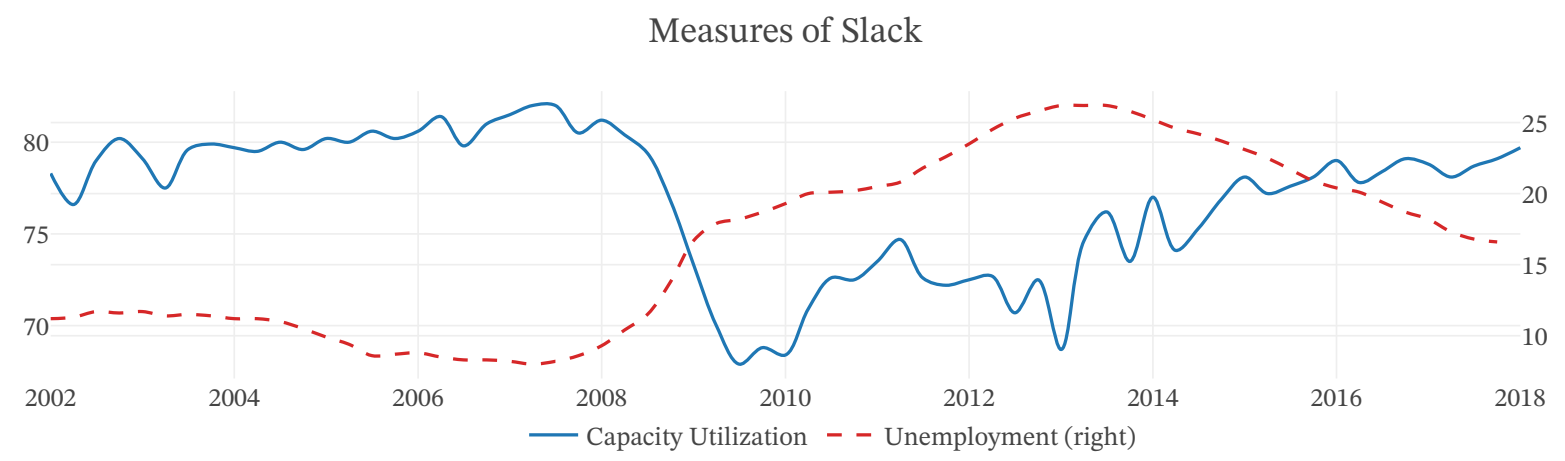

Figure 20: SLACK IN THE Spanish ECONOMY

Source: Eurostat

Factors Limiting Production

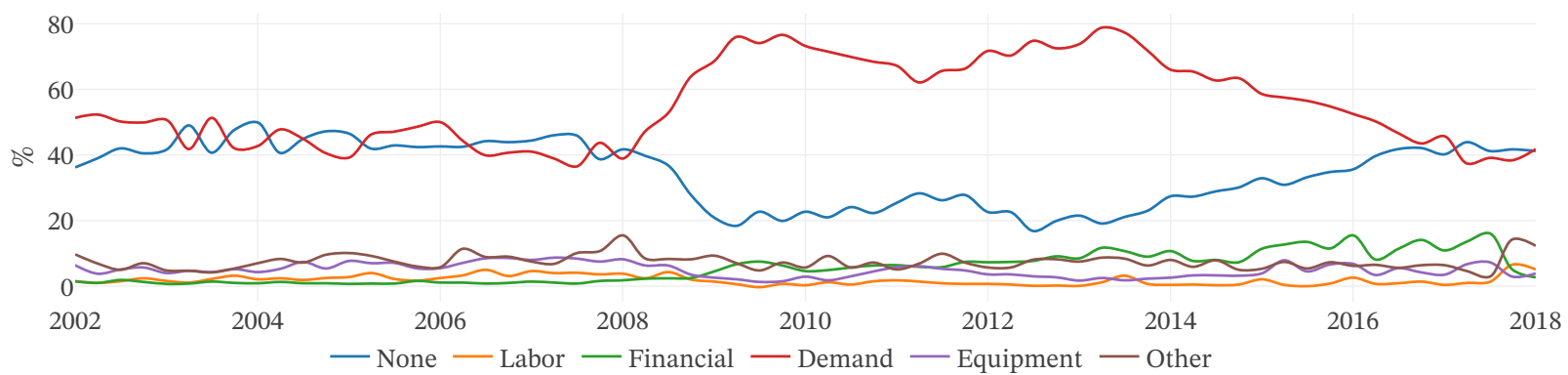

Figure 21: Spanish Firms' Self-reported Limits to Production

Source: Eurostat 
Borrowing rates

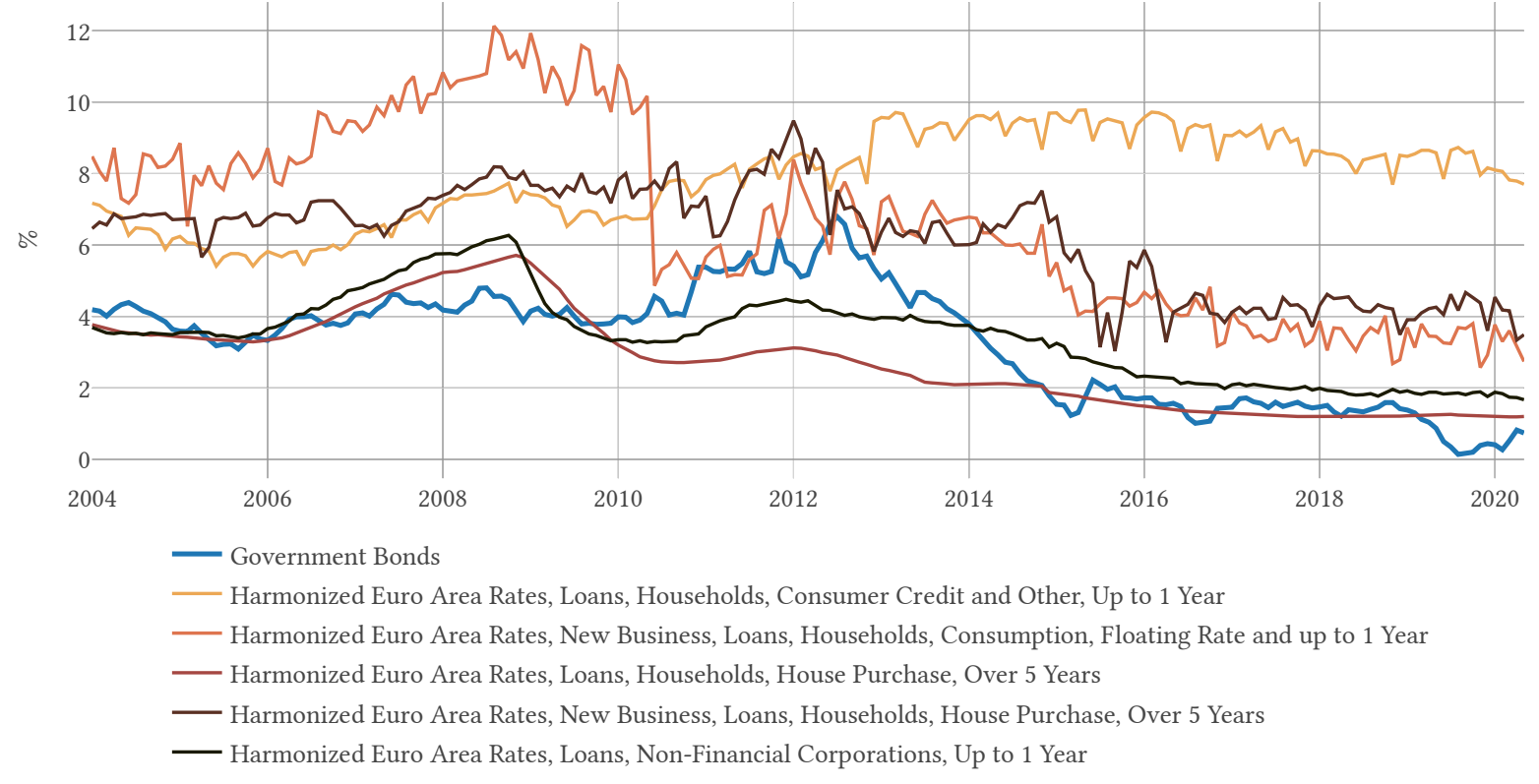

Deposit rates

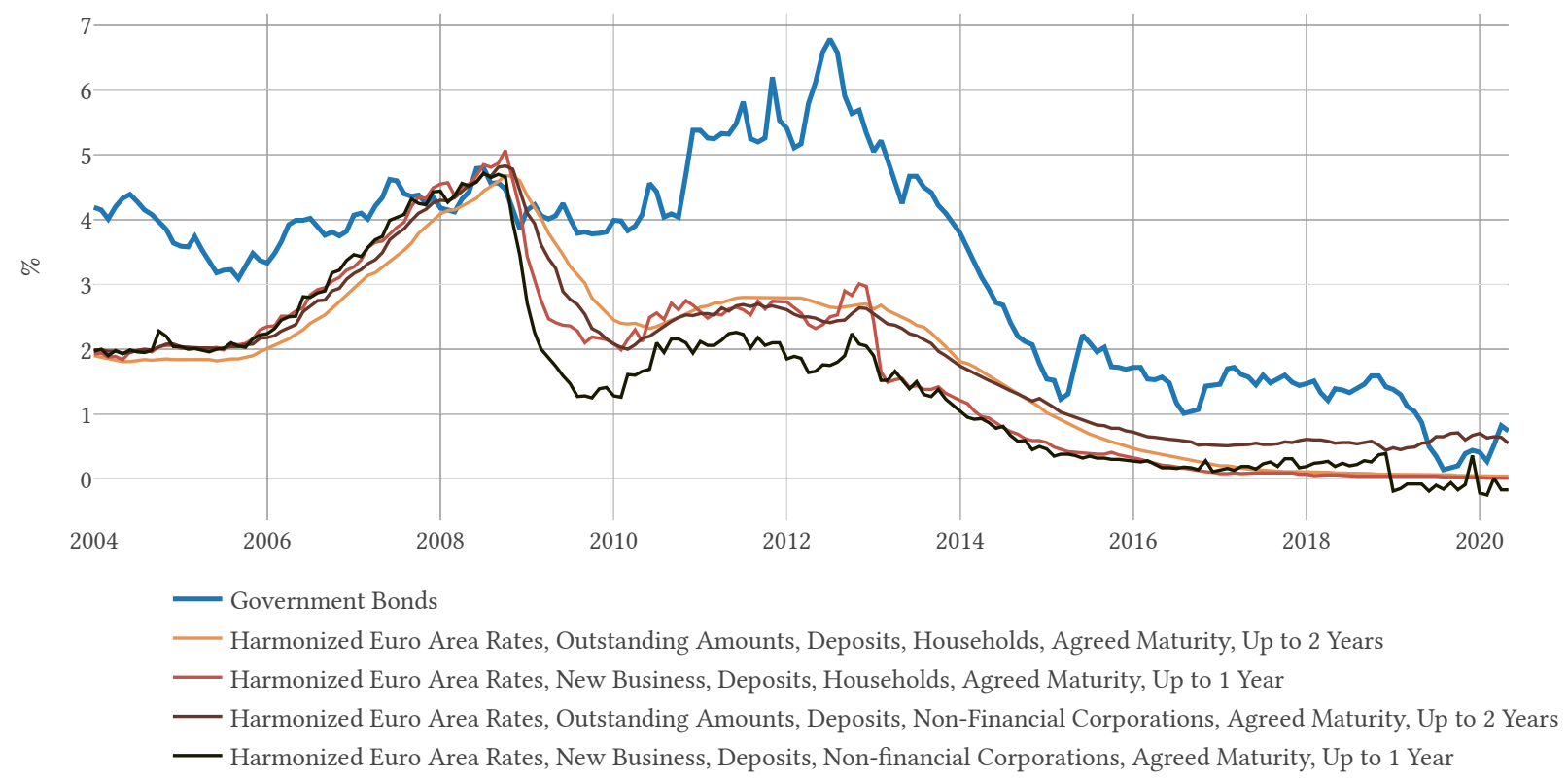

FIgURE 22: INTEREST RATES IN SPAIN

Source: IMF IFS 


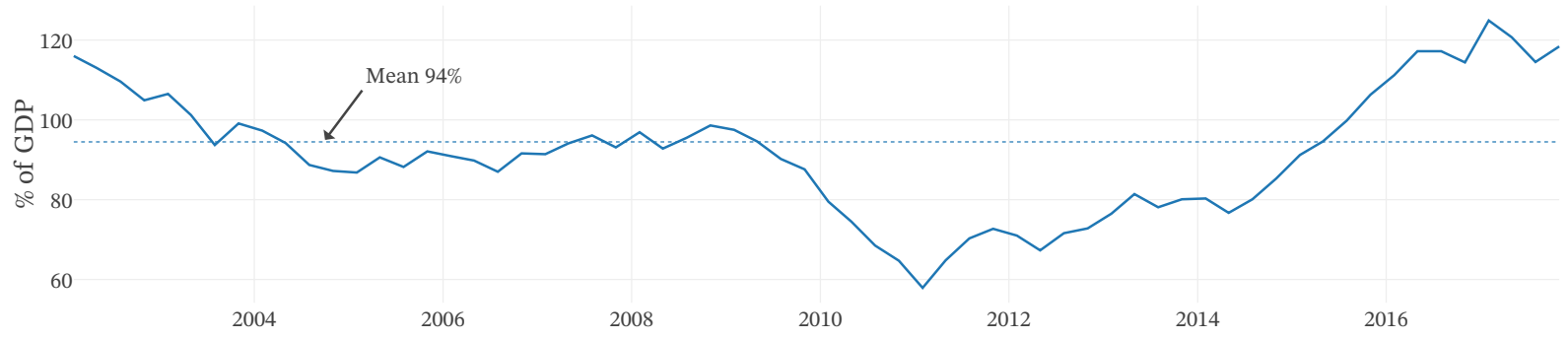

Figure 23: Net Worth of Spanish Households

Source: Eurostat

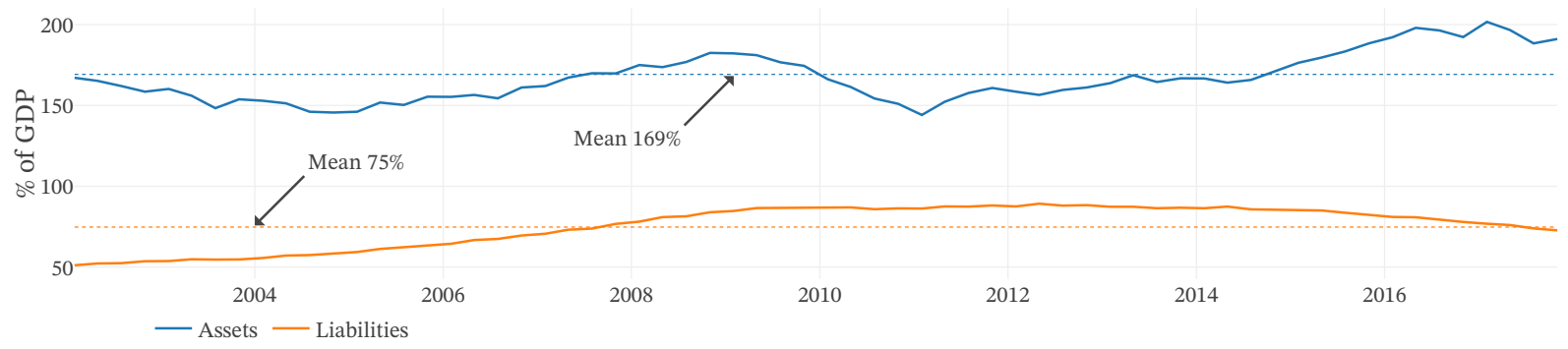

Figure 24: Net Worth of Spanish Households

Source: Eurostat

\begin{tabular}{lcccc}
\hline & $\sigma(C)$ & $\sigma(Y)$ & $\sigma(C) / \sigma(Y)$ & $\sigma(C) / \sigma(Y)(\mathrm{AG})$ \\
\hline Austria & 0.716 & 0.782 & 0.916 & 0.870 \\
Belgium & 0.556 & 0.795 & 0.700 & 0.810 \\
Denmark & 1.047 & 1.178 & 0.889 & 1.190 \\
Finland & 1.278 & 1.957 & 0.653 & 0.940 \\
France & 0.780 & 0.773 & 1.009 & - \\
Germany & 0.692 & 0.867 & 0.799 & - \\
Ireland & 3.140 & 3.680 & 0.853 & - \\
Italy & 1.165 & 0.978 & 1.191 & - \\
Netherlands & 1.726 & 1.244 & 1.388 & 1.070 \\
Portugal & 1.827 & 1.576 & 1.160 & 1.020 \\
Spain & 1.901 & 1.396 & 1.362 & 1.110 \\
\hline
\end{tabular}

Series logged and HP-filtered with $\lambda=1600$. Std deviations in $\%$.

Table 8: The Cycle is the Trend 
Filtered Spanish output and consumption

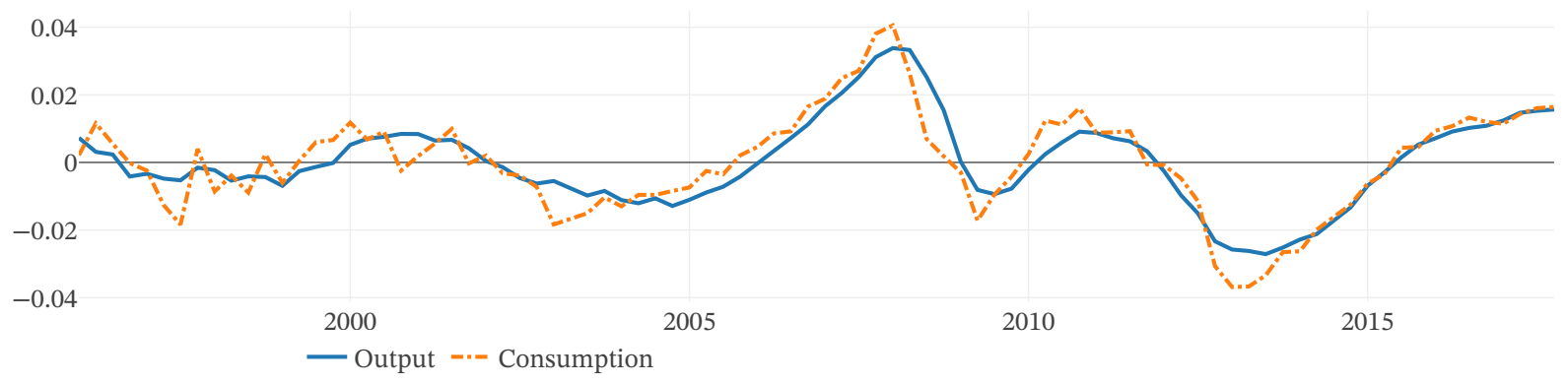

Figure 25: SPANISH DETRENDED OUTPUT AND CONSUMPTION IN THE $2000 \mathrm{~S}$

Trade balance for Spain

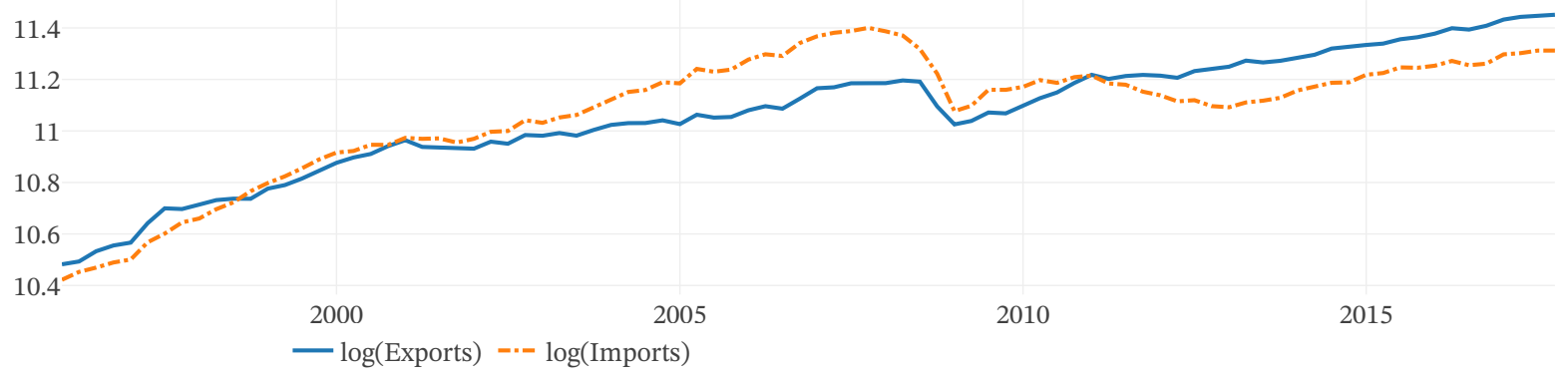

Figure 26: SPANISH TRADE BALANCE IN THE $2000 \mathrm{~S}$

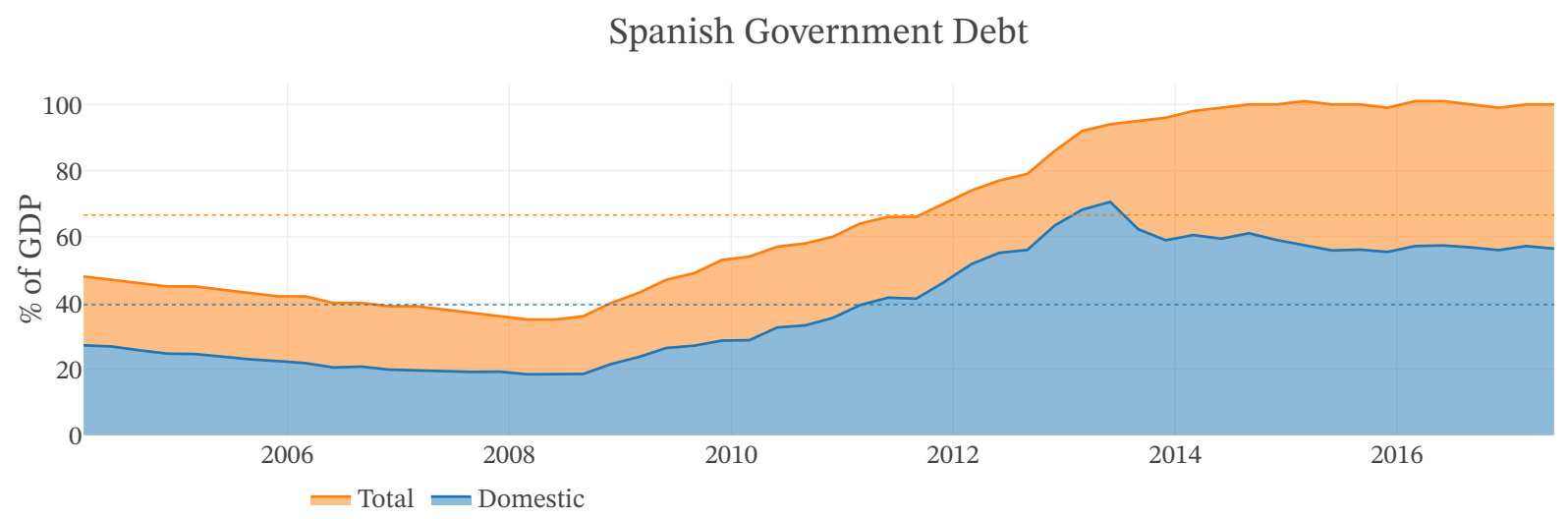

Figure 27: Composition of Spanish DebT

Dotted lines show average levels 


\section{Appendix: Data sources}

\begin{tabular}{lccc}
\hline Variable & Source & Coverage & Code \\
\hline GDP & Eurostat & 1996Q1:2017Q4 & namq_10_gdp \\
HH Consumption & OECD & $1996 \mathrm{Q}_{1: 2017} 4$ & \\
Imports & Eurostat & $1996 \mathrm{Q}_{1: 2017} 4$ & namq_10_gdp \\
Exports & Eurostat & $1996 \mathrm{Q}_{1}: 2017 \mathrm{Q}_{4}$ & namq_10_gdp \\
Government Spending & Eurostat & $1996 \mathrm{Q}_{1: 2017} 4$ & namq_10_gdp \\
Government Debt & Eurostat & $1996 \mathrm{Q}_{1: 2017} 4$ & gov_10q_ggdebt \\
Interest Rate on Gov't Bonds & Eurostat & $1996 \mathrm{Q}_{1: 2017} 4$ & irt_1t_mcby_q \\
Unemployment & Eurostat & $1996 \mathrm{Q}_{1: 2017} 4$ & une_rt_q \\
Spanish HHs' wealth & Eurostat & $1998 \mathrm{Q}_{4}: 2018 \mathrm{Q}_{2}$ & nasq_10_f_bs \\
Spain's Debt Composition & Banco de España & 2004Q1:2017Q4 & \\
\hline
\end{tabular}

Table 9: Data Sources 